\title{
Optimization of the crankshaft using finite element analysis approach
}

\author{
V. C. Shahane ${ }^{1} \cdot$ R. S. Pawar ${ }^{2}$
}

Received: 30 August 2016/Accepted: 21 November 2016/Published online: 1 December 2016

(C) Springer International Publishing Switzerland 2016

\begin{abstract}
Crankshaft is one of the most critical components for effective and precise working of the internal combustion engine. In this paper, a static structural and dynamic analysis was conducted on a single cylinder fourstroke diesel engine crankshaft. A solid model of the crankshaft was created using higher-end computer-aided design software, i.e., Pro/Engineer software according to the dimensional details drawing of the existing crankshaft. Finite element analysis was performed using ANSYS software under the static and dynamic condition to obtain the variation of stresses at different critical locations of the crankshaft. Boundary conditions were applied on finite element model in accordance with engine specification chart and engine mounting conditions. Optimization of the crankshaft was studied in the area of geometry and shape on the existing crankshaft; however especially working on geometry and shape optimization, the optimized crankshaft design should be replaced with existing crankshaft, without changes in the engine block and cylinder head. The optimized crankshaft helps to improve the performance of the engine and causes reduction in weight. This optimization study of the crankshaft helps to reduce $4.37 \%$ of the weight in the original crankshaft.
\end{abstract}

V. C. Shahane

shahane2004@gmail.com

R. S. Pawar

Principal@sycet.org

1 Department of Mechanical Engineering, Shreeyash College of Engineering and Technology, Aurangabad, M.S., India

2 Shreeyash College of Engineering and Technology, Aurangabad, M.S., India
Keywords Diesel engine $\cdot$ Crankshaft $\cdot$ Structural analysis · Dynamic analysis - Computer-aided design . Finite element analysis - ANSYS

\section{Introduction}

The crankshaft is one of the most important moving parts in the internal combustion engine. Crankshaft is a large component with a complex geometry consisting of bearing plates as the crank webs and balancing mass in the engine, which converts the reciprocating displacement of the piston into rotary motion. This study was conducted on a single cylinder four-stroke diesel engine. The crankshaft must be strong enough to take the downward force during power stroke without excessive bending. Thus, the reliability and life of the internal combustion engine depend largely on the strength of the crankshaft. The crankshaft is the large volume production part; hence an optimized design is an effective method to increase the fuel efficiency and overall cost of the engine; However as the engine runs, the power impulses hit the crankshaft in one place and then another. The torsional vibration appears when a power impulse hits a crankpin toward the front of the engine and the power stroke ends. If not controlled, it can break the crankshaft. A solid three-dimensional parametric geometry of a single cylinder crankshaft of a four-stroke diesel engine is created using higher-end CAD software, i.e., Pro/Engineer according to the detailed two-dimensional drawing. This solid geometry was imported in step format for finite element simulation purpose under structural and dynamic simulation using ANSYS workbench software. The static and dynamic analyses on the existing design were done to verify the results under static and dynamic conditions by applying boundary conditions according to engine specification and 
crankshaft mounting condition. The finite element analysis results were verified theoretically and numerically. However, these results were most important as a benchmark for further optimization study of the crankshaft. The optimization was studied by consideration and effects of geometry and shape on the counter weight and crankpin without affecting mounting on the engine block and cylinder head in the existing design crankshaft. Hence, different feasibility optimization cases were evaluated in the present crankshaft design using computer-aided design and finite element analysis approach. Furthermore, optimized case results of crankshaft were compared with the results of the benchmark crankshaft [1-5].

\section{Engine specifications and boundary conditions}

See Table 1.

Calculation of the forces on the single cylinder engine crankshaft:

- Force on the piston:

$\mathrm{Fp}=$ area of the bore $\times$ maximum combustion pressure.

$\mathrm{Fp}=\pi / 4 \times D^{2} \times P_{\max }=14.52 \mathrm{KN}$.

To find the thrust in the connecting rod, $F_{\mathrm{c}}$, we should first find out the angle of inclination of the connecting rod with the line of stroke.

- Thrust on the connecting rod:

$F_{\mathrm{c}}=F_{\mathrm{p}} / \operatorname{Cos} \theta$,

where, $\theta=$ angle of inclination of the connecting rod with the line of stroke, $\operatorname{Sin} \varnothing=\operatorname{Sin} \theta /(L / R), \theta=$ maximum crank angle $=355^{\circ}, L / R=3.29, F_{\mathrm{c}}=14.527 \mathrm{KN}$.

The force on the crankshaft can be split into tangential and radial components.

- Tangential force on the crankshaft:

$$
F_{\mathrm{t}}=F_{\mathrm{c}} \times \operatorname{Cos}(\theta+\varnothing)=14.49 \mathrm{KN} .
$$

Table 1 Specification of single cylinder diesel engine

\begin{tabular}{|c|c|}
\hline Parameter & Specification \\
\hline Capacity & $435 \mathrm{CC}$ \\
\hline Number of cylinders & 1 \\
\hline Bore $\mathrm{x}$ stroke & $86 \times 75 \mathrm{~mm}$ \\
\hline Compression ratio & 19:01 \\
\hline Maximum power & 7.5 HP@3600 RPM \\
\hline Maximum torque & 18NM@2400 RPM \\
\hline Maximum gas pressure & 25 Bar \\
\hline Engine speed & $63.73 \mathrm{kmph}$ \\
\hline
\end{tabular}

- Radial force on the crankshaft:

$F_{\mathrm{r}}=F_{\mathrm{c}} \times \operatorname{Sin}(\theta+\varnothing)=0.88 \mathrm{KN}$.

Reaction at bearings 1 and 2 due to tangential force is given by

- $H_{\mathrm{T} 1}=H_{\mathrm{T} 2}=\left(F_{\mathrm{t}} \times b_{1}\right) / b=7.245 \mathrm{KN}$.

Similarly, reactions at bearings 1 and 2 due to radial force is given by

- $H_{\mathrm{R} 1}=H_{\mathrm{R} 2}=\left(F_{\mathrm{r}} \times b_{1}\right) / b=0.44 \mathrm{KN}$.

The boundary conditions were applied as per mounting of the crankshaft by assuming that there is no change in the engine block and cylinder head [6-10].

\section{Static structural and dynamic analysis of the original crankshaft}

Static structural analysis of the existing crankshaft was done using the finite element analysis approach. The finite element method is a numerical analysis technique for obtaining approximate solutions to a wide variety of engineering problems, because of its diversity and flexibility as an analysis tool. It is receiving much attention in engineering school and industries. In more and more engineering situations today, we find that it is necessary to obtain approximate solutions to problems rather than the exact closed form solution (Figs. 1, 2, 3, 4, 5, 6).

The static structural analysis of the existing crankshaft was done using ANSYS workbench to evaluate the different stresses and deformations under static loading conditions. Finite element analysis involves four main steps to solve any physics problem using ANSYS software (http://www.ANSYS.COM).

1. Preliminary decisions

2. Preprocessing

3. Solution

4. Postprocessing

- Preliminary decisions Before solving any engineering problem using software, we need to make few decisions, such as analysis type, type of CAD data and element type.

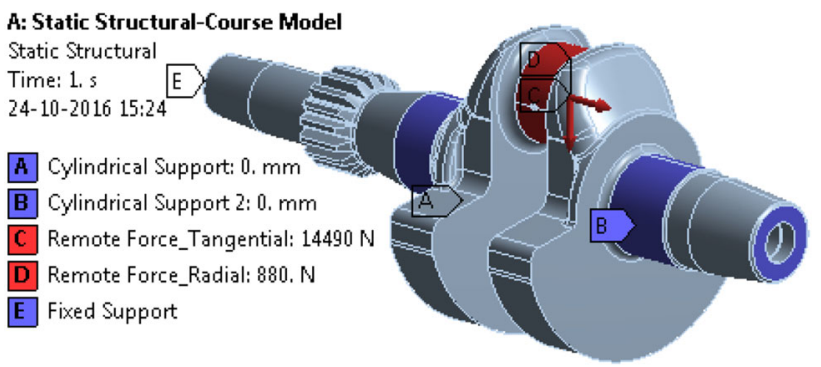

Fig. 1 Boundary conditions 


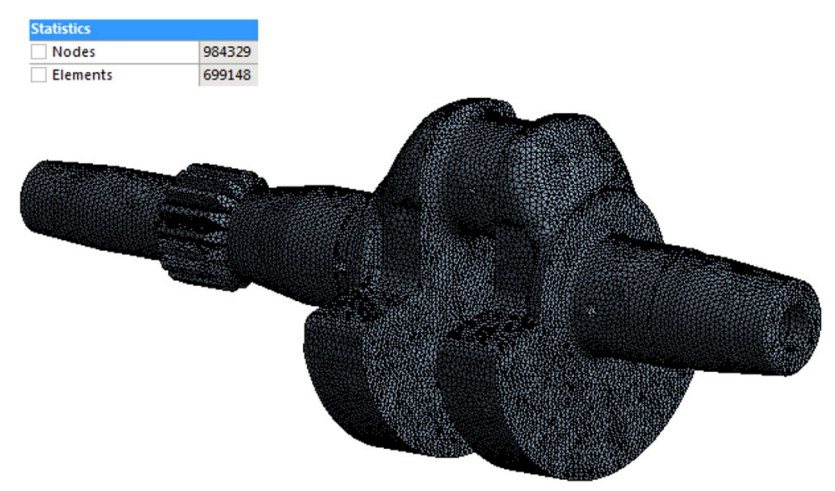

Fig. 2 Geometry of mesh

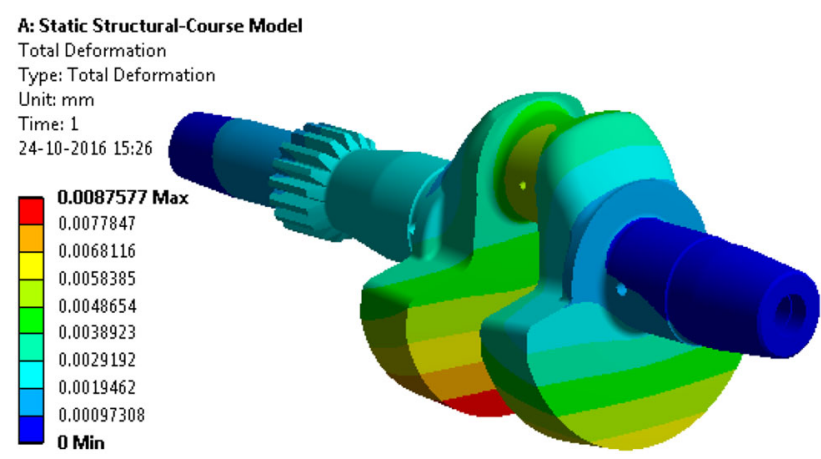

Fig. 3 Total deformation

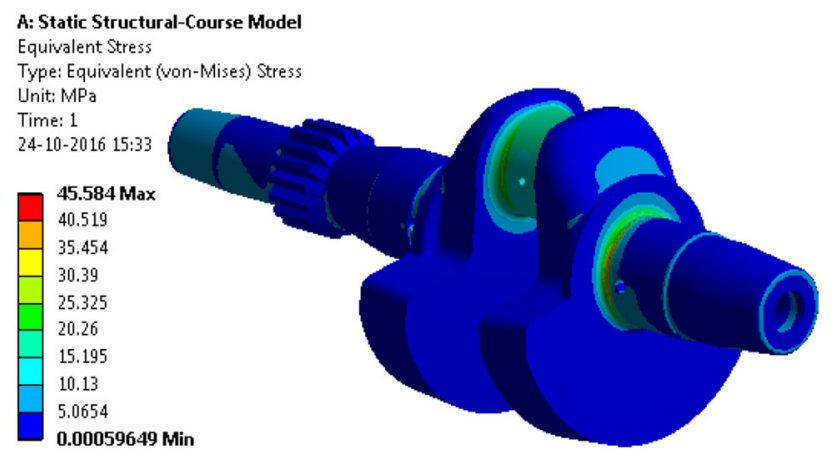

Fig. 4 Equivalent stress

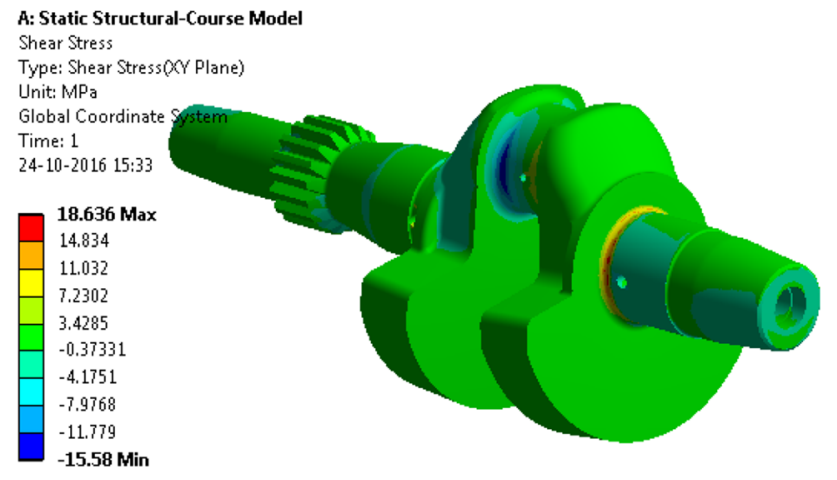

Fig. 5 Shear stress

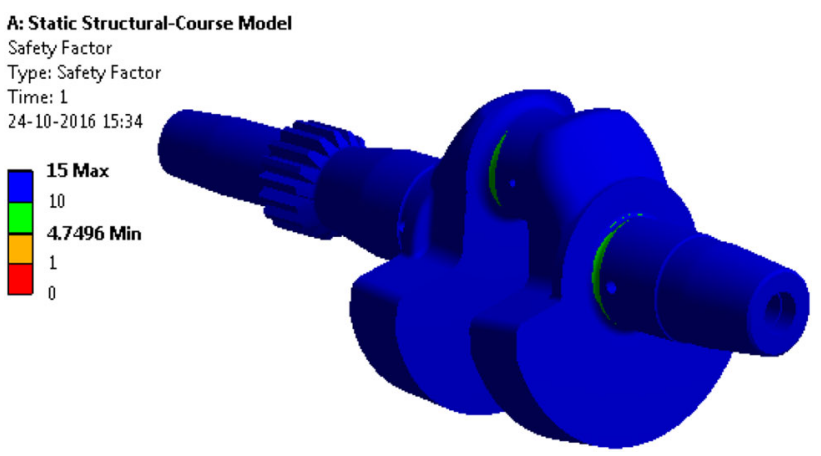

Fig. 6 Safety factor

- Preprocessing As the name indicates, preprocessing is something the designer does before the processing analysis. In this stage, material properties, create/ import geometry and mesh plot are necessary to compute an engineering problem.

- Solution The solution is the step in finite element analysis simulation to apply boundary conditions in the form of restraints and loads.

a. Postprocessing The postprocessing stage deals with the representation of results. Typically, the deformed configuration, mode shapes, temperature and stress distribution are computed and displayed at this stage.

1. Preliminary decisions:
a. Analysis type: static structural analysis
b. CAD data: three-dimensional solid model
c. Element type: Solid95

2. Preprocessing
a. Define material: structural steel
b. Import geometry
c. Mesh geometry: tet10

3. Solution
a. Apply load: load and boundary conditions applied as per engine specification
b. Solve: linear analysis physics problem

4. Postprocessing
a. Total deformation
b. Von Mises stress
c. Shear stress
d. Safety factor

\subsection{Dynamic analysis of the original crankshaft}

Modal analysis is a technique to study the dynamic characteristic of a structure under vibrational excitation. Modal analysis is the most fundamental of all dynamic 
analysis types and is generally the starting point for other, more detailed dynamic analysis. Modal analysis is used to determine a structure's vibration characteristic like natural frequencies and mode shapes. Modal analysis allows the design to avoid resonant vibrations or to vibrate at a specified frequency and gives engineers an idea of how the design will respond to different types of dynamic loads. The crankshaft of an engine is one such structure whose dynamic characteristics can be better studied by modal analysis. The objective of this study was to determine the natural frequencies and its mode shape of single cylinder engine of the existing and optimized crankshaft. Modal analysis of crankshaft was carried out by using finite element software, i.e., ANSYS workbench. The benefits of using finite element software were that mode shapes could be accurately visualized and simulated. So, deformations occurs in the crankshaft could be located precisely [11-23].

An average operating engine speed is $63.73 \mathrm{kmph}$. The effect of damping is a very negligible influence on natural frequency of the crankshaft, hence damping coefficient was not considered in the free vibration of the crankshaft. However, another aspect was considered during free vibration of the crankshaft calculation, as the crankshaft was supported by ball bearings to both sides so the effect of hysteretic damping, i.e., due to internal friction of the bearing and crankshaft, was minor. Hence, the damping effect is ignored in free vibration of the crankshaft. In general, the equation of motion of single degree of a system with damping under the vibration is given by

$[m] \ddot{u}+[c] \stackrel{\circ}{u}+[k] u=0$,

$\ddot{u}+2 \zeta \omega_{n} \stackrel{u}{u}+\omega_{n}^{2} u=0$,

where

$\omega_{n}=\sqrt{k / m}$ is the undamped natural frequency.

$c_{\mathrm{c}}=2 \sqrt{ } \mathrm{km}$ is the critical damping, i.e., the threshold between oscillatory and non-oscillatory behavior.

$\zeta=c / c_{\mathrm{c}}$ is the damping ratio, i.e., the ratio of damping in a system to the critical damping.

$\omega_{\mathrm{d}}=\omega_{\mathrm{n}} \sqrt{1-\zeta}$ is the frequency of damped oscillation [1].

The following is the procedure for modal analysis of the crankshaft under dynamic loading conditions (Figs. 7, 8, 9, $10,11,12,13,14,15,16,17)$.

1. Preliminary decisions

a. Analysis type: modal analysis

b. CAD data: three-dimensional solid model

c. Element type: Solid95

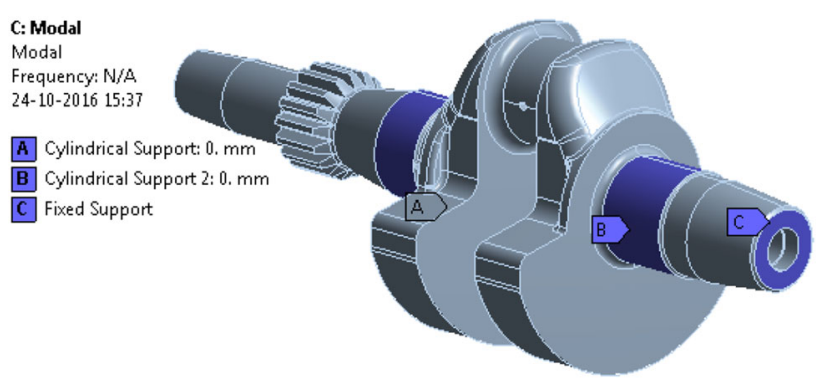

Fig. 7 Boundary condition

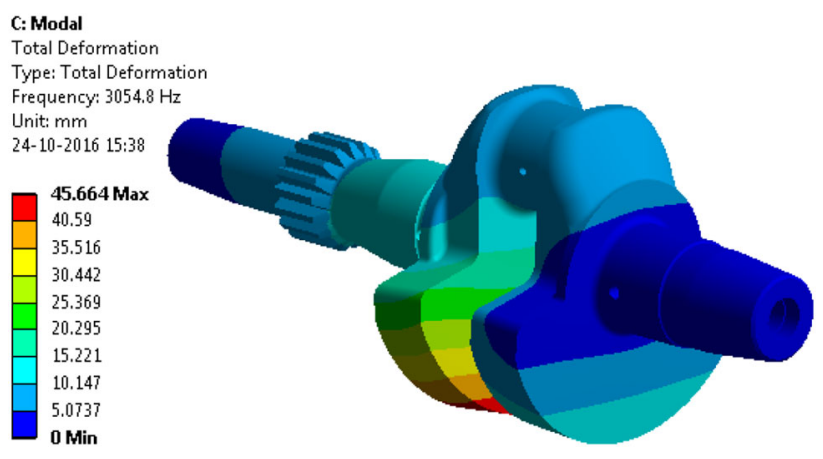

Fig. 8 First mode and deformation

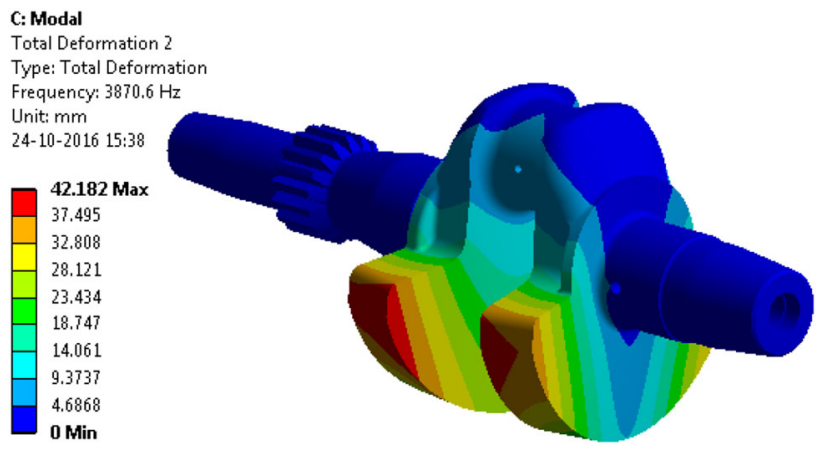

Fig. 9 Second mode and deformation

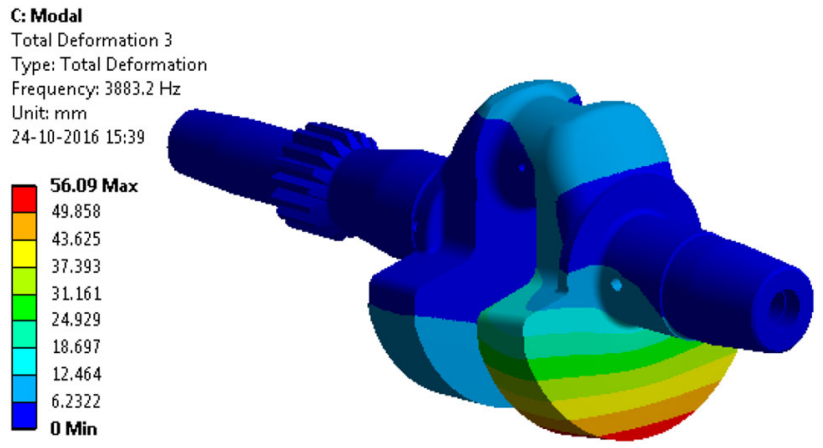

Fig. 10 Third mode and deformation 


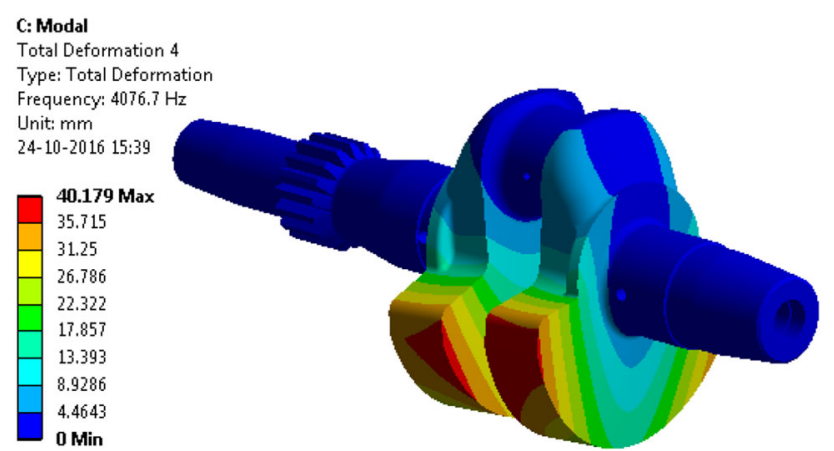

Fig. 11 Fourth mode and deformation

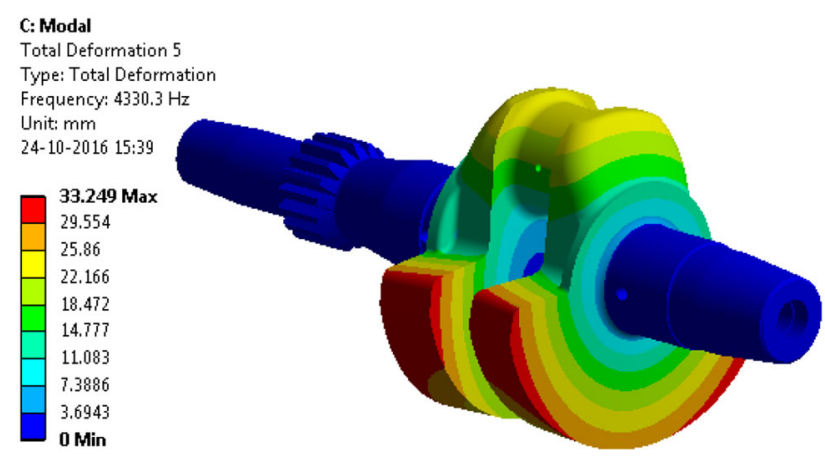

Fig. 12 Fifth mode and deformation

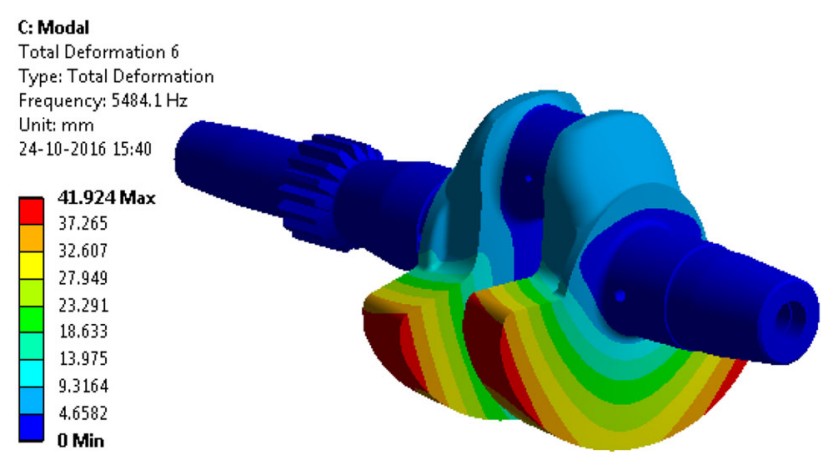

Fig. 13 Sixth mode and deformation

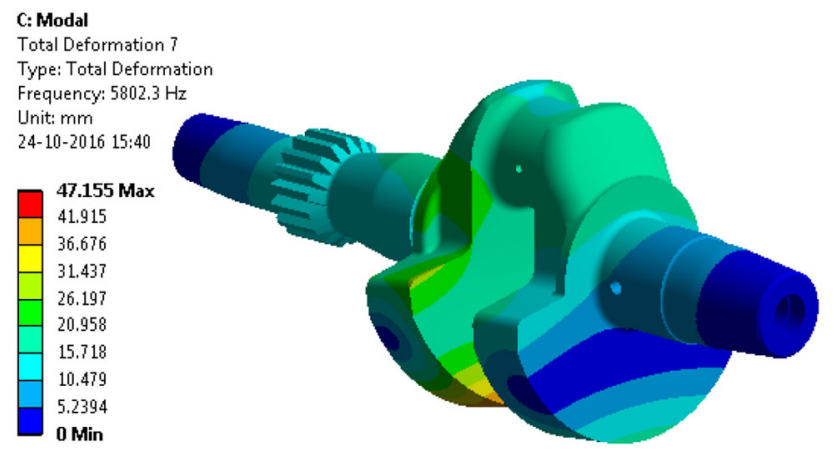

Fig. 14 Seventh mode and deformation

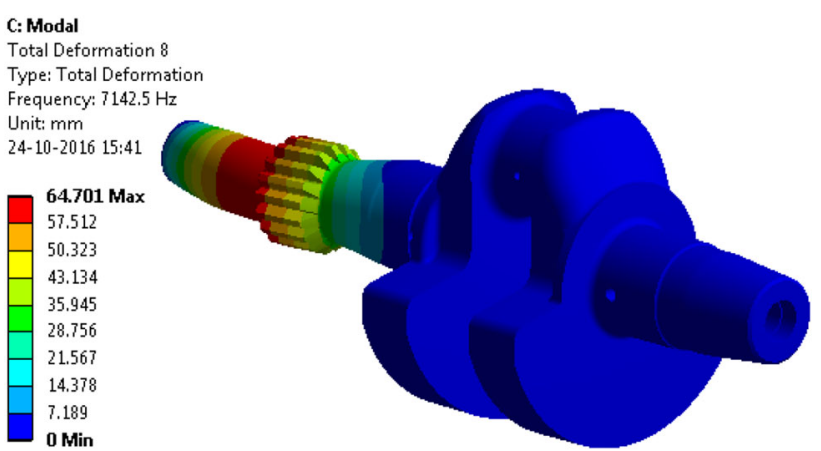

Fig. 15 Eighth mode and deformation

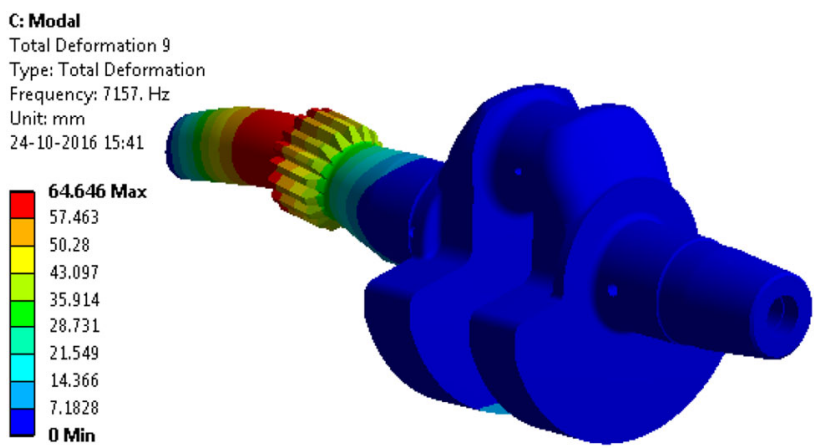

Fig. 16 Ninth mode and deformation

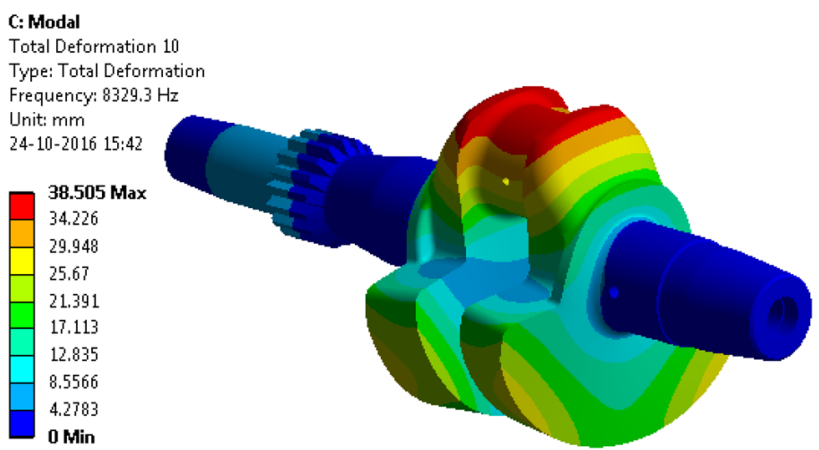

Fig. 17 Tenth mode and deformation

2. Preprocessing
a. Define material:structural steel
b. Import geometry
c. Mesh geometry: tet10

3. Solution
a. Apply load: cylindrical supports and fixed support
b. Solve: linear analysis physics problem

4. Post processing
a. Natural mode shapes
b. Natural frequencies
c. Deformation 
Table 2 Frequencies and corresponding modes

\begin{tabular}{lll}
\hline Mode & Frequency $(\mathrm{Hz})$ & Type of mode \\
\hline 1 & 3054.8 & Bending \\
2 & 3870.6 & Torsion \\
3 & 3883.2 & Bending + torsion \\
4 & 4076.7 & Torsion \\
5 & 4330.3 & Bending + torsion \\
6 & 5484.1 & Torsion \\
7 & 5802.3 & Bending + torsion \\
8 & 7142.5 & Torsion \\
9 & 7157 & Torsion \\
10 & 8329.3 & Bending + torsion \\
\hline
\end{tabular}

\subsection{Result of modal analysis}

See Table 2.

\section{Case 1: static structural and dynamic analysis of the optimized crankshaft}

The original crankshaft is optimized by removed the material from the crankpin geometry with the technical assumptions and manufacturing aspects by considered $20 \mathrm{~mm}$ drilled diameter. Figure 18 shows the the optimized geometry details.

\subsection{Static structural analysis results}

See Figs. 19, 20, 21 and 22.

\subsection{Modal analysis results}

See Figs. 23, 24, 25, 26, 27, 28, 29, 30, 31 and 32.

\subsection{Result of modal analysis}

See Table 3.

\section{Case 2: static structural and dynamic analysis of the optimized crankshaft}

The existing crankshaft was optimized by dimensional changes in the counterweight geometry with angle $12^{\circ}-$ $22^{\circ}$. Figure 33 show the optimized geometry details.

\subsection{Static structural analysis results}

See Figs. 34, 35, 36 and 37.

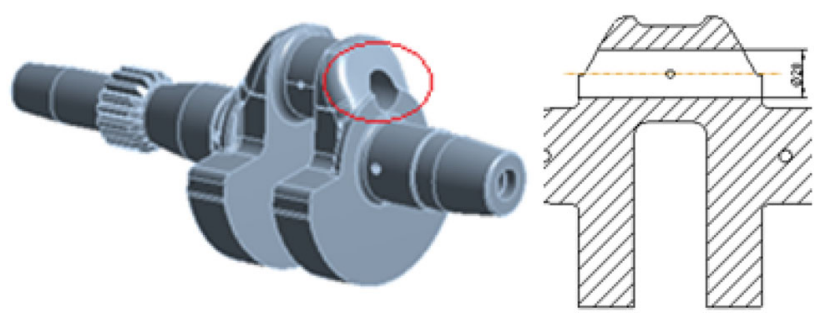

Fig. 18 Case 1: optimized geometry

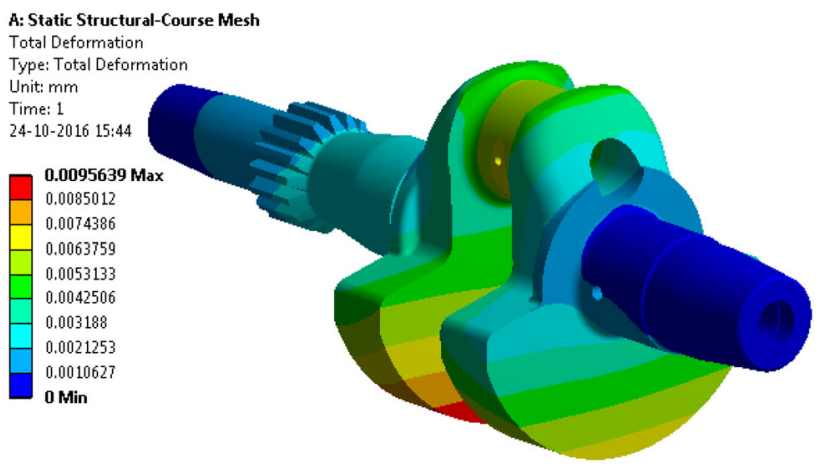

Fig. 19 Total deformation

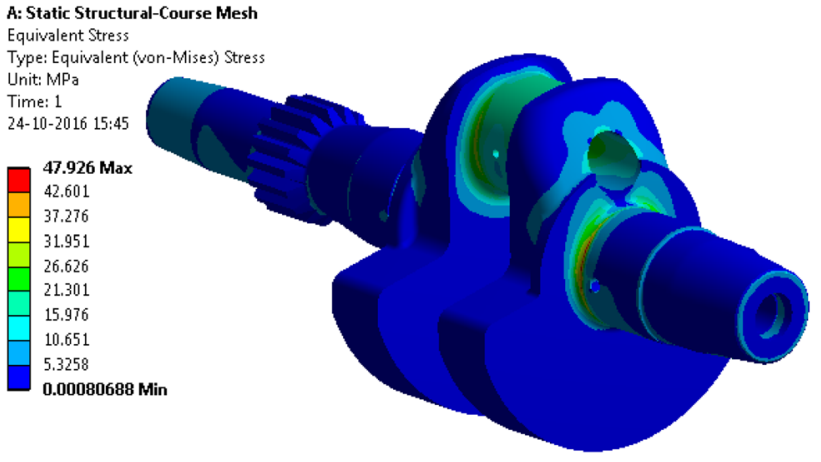

Fig. 20 Equivalent stress

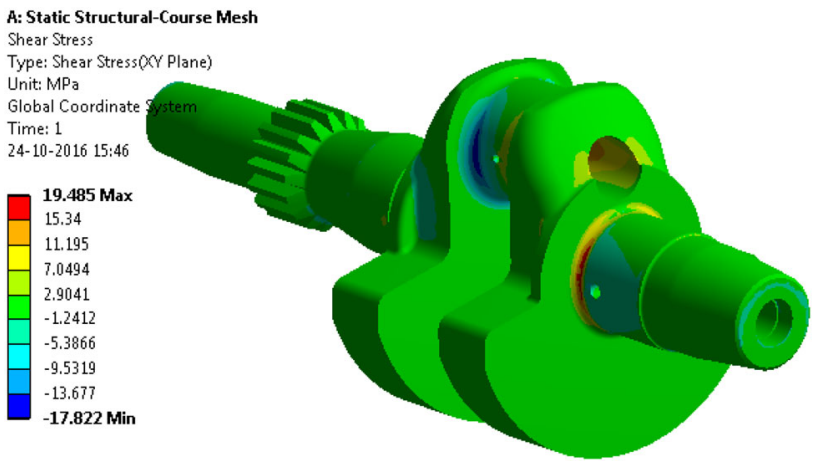

Fig. 21 Shear stress

\subsection{Modal analysis results}

See Figs. 38, 39, 40, 41, 42, 43, 44, 45, 46 and 47. 


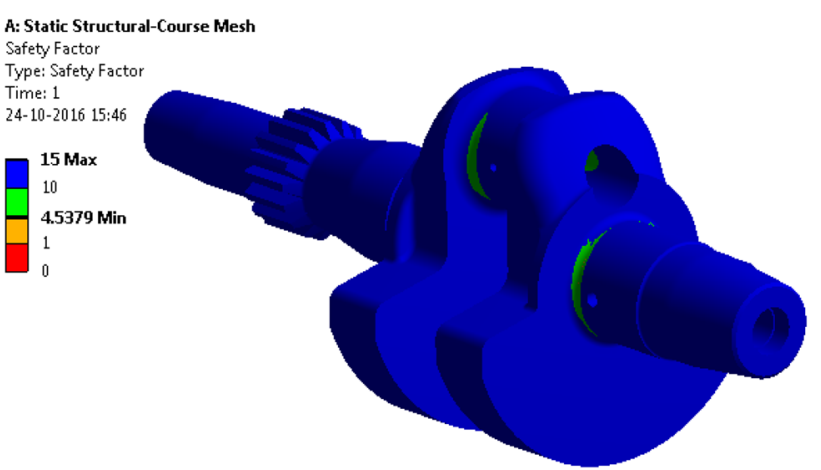

Fig. 22 Safety factor

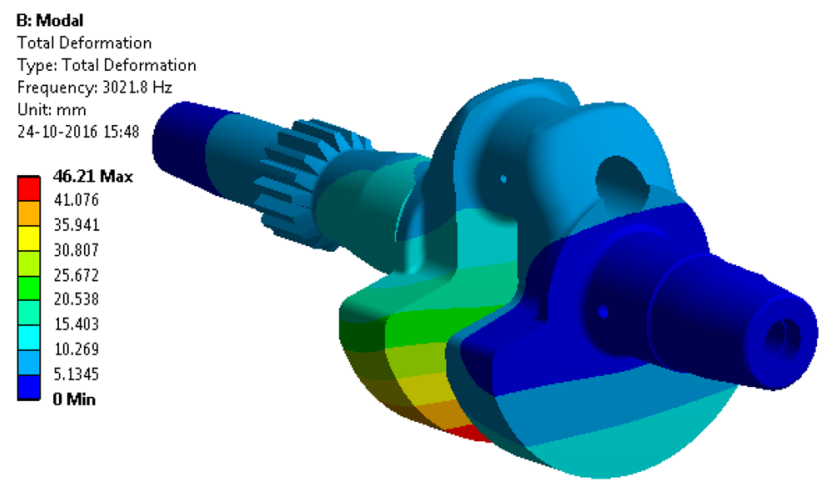

Fig. 23 First mode and deformation

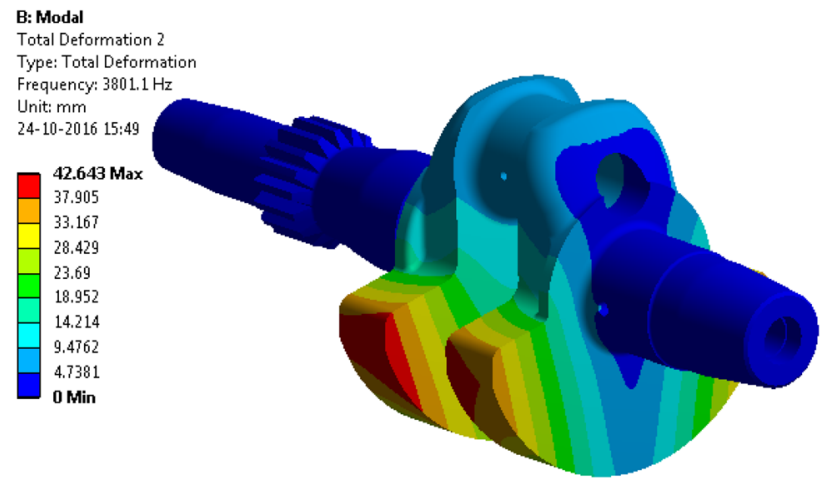

Fig. 24 Second mode and deformation

\subsection{Result of modal analysis}

See Table 4.

\section{Case 3: static structural and dynamic analysis of the optimized crankshaft}

The existing crankshaft was optimized by dimensional changes in counterweight geometry and material removed from the crankpin with combination considered in cases 1 and 2. Figure 48 shows the optimized geometry details.

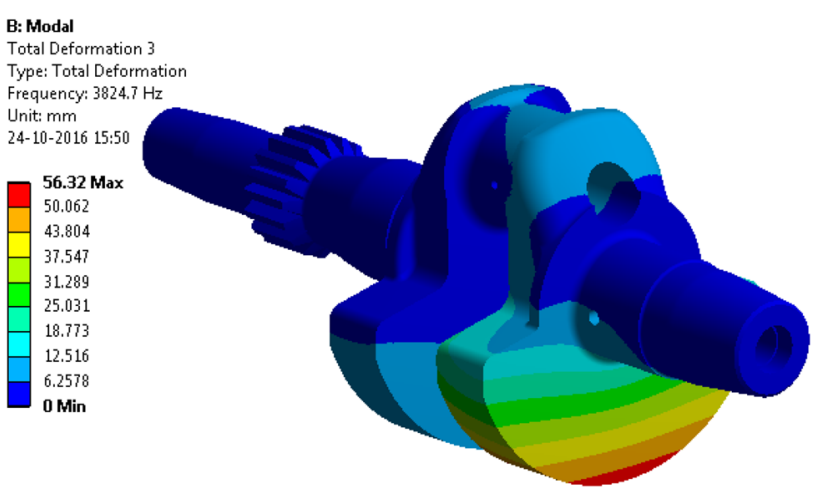

Fig. 25 Third mode and deformation

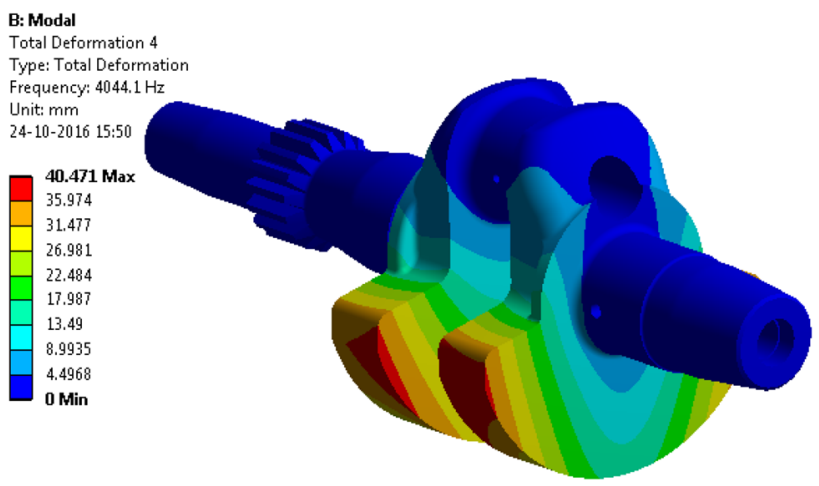

Fig. 26 Fourth mode and deformation

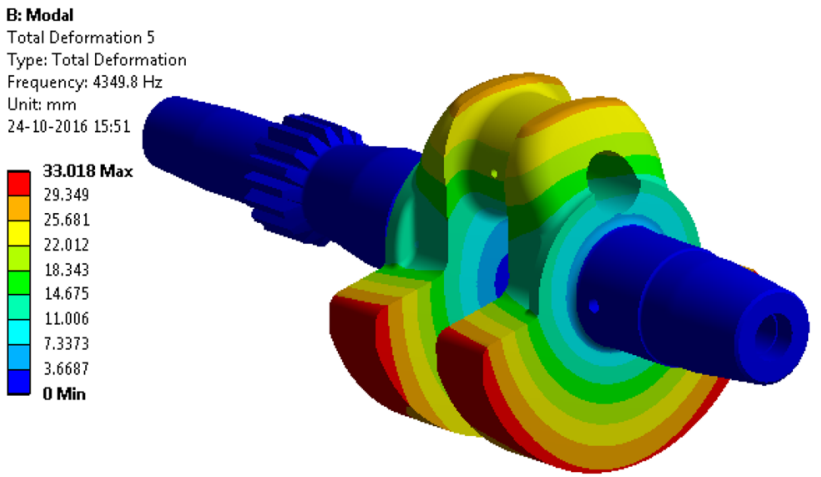

Fig. 27 Fifth mode and deformation

\subsection{Static structural analysis results}

See Figs. 49, 50, 51 and 52.

\subsection{Modal analysis results}

See Figs. 53, 54, 55, 56, 57, 58, 59, 60, 61 and 62.

\subsection{Result of modal analysis}

See Table 5. 


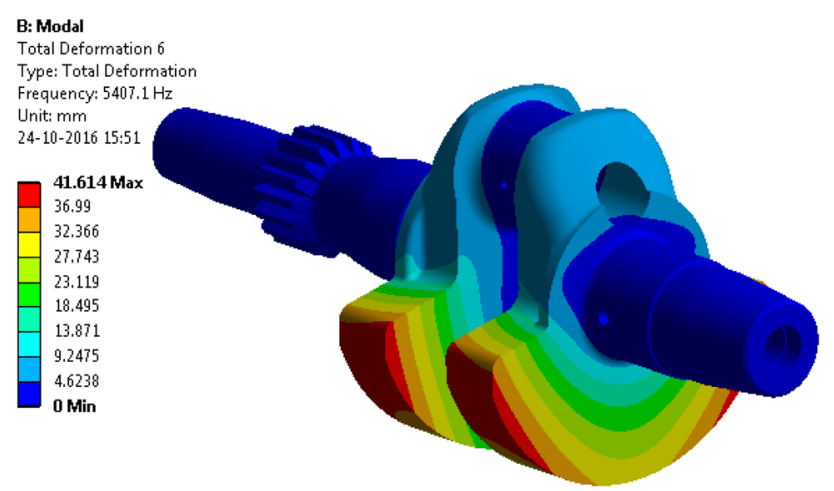

Fig. 28 Sixth mode and deformation

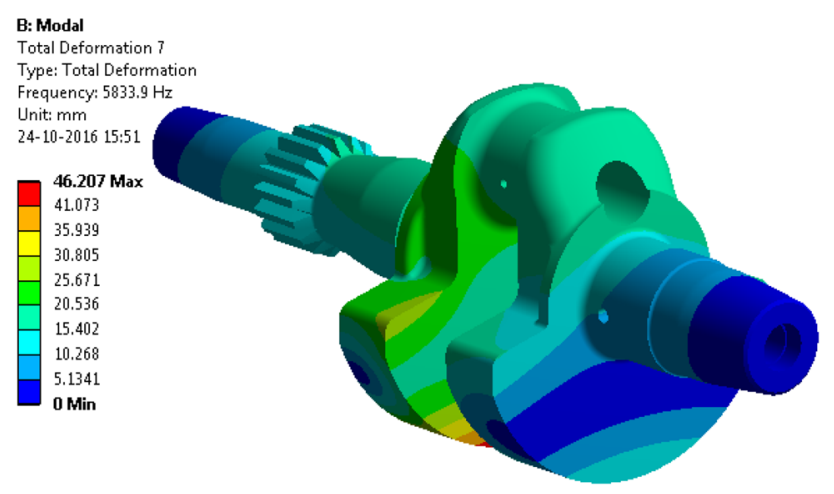

Fig. 29 Seventh mode and deformation

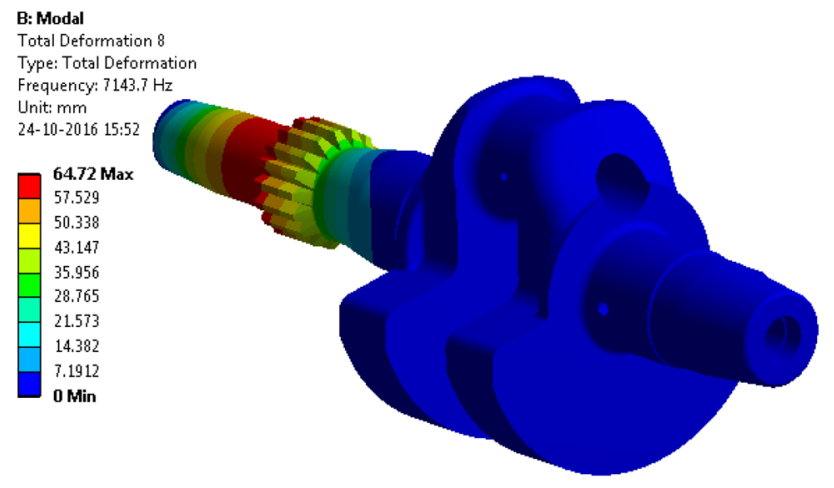

Fig. 30 Eight mode and deformation

\section{Case 4: static structural and dynamic analysis of the optimized crankshaft}

The existing crankshaft was optimized by $5 \mathrm{~mm}$ material removed from the web from both sides of the counterweight geometry. Figure 63 shows the optimized geometry details.

\subsection{Static structural analysis results}

See Figs. 64, 65, 66 and 67.

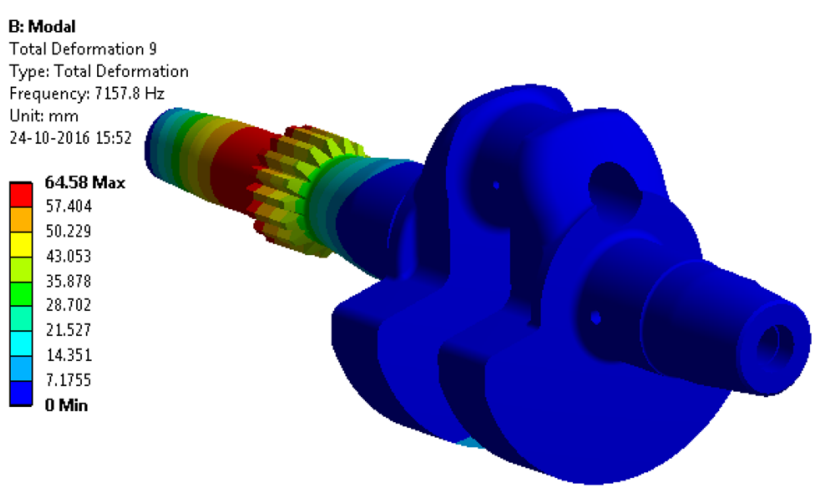

Fig. 31 Nineth mode and deformation

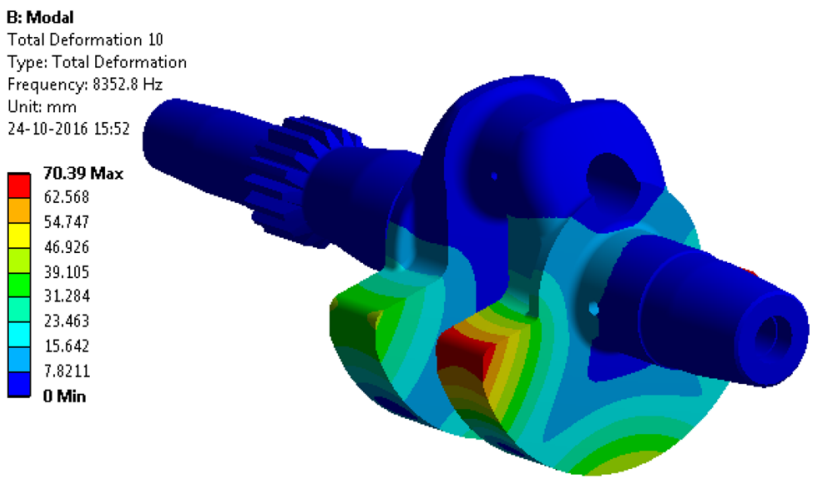

Fig. 32 Tenth mode and deformation

Table 3 Frequencies and corresponding modes

\begin{tabular}{lll}
\hline Mode & Frequency $(\mathrm{Hz})$ & Type of mode \\
\hline 1 & 3021.8 & Bending \\
2 & 3801.1 & Torsion \\
3 & 3824.7 & Bending + torsion \\
4 & 4044.1 & Torsion \\
5 & 4349.8 & Bending + torsion \\
6 & 5407.1 & Torsion \\
7 & 5833.9 & Bending + torsion \\
8 & 7143.7 & Torsion \\
9 & 7157.8 & Torsion \\
10 & 8352.8 & Bending + torsion
\end{tabular}

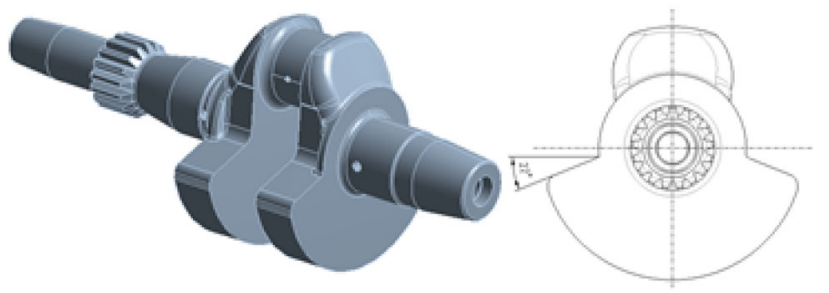

Fig. 33 Case 2: optimized geometry 

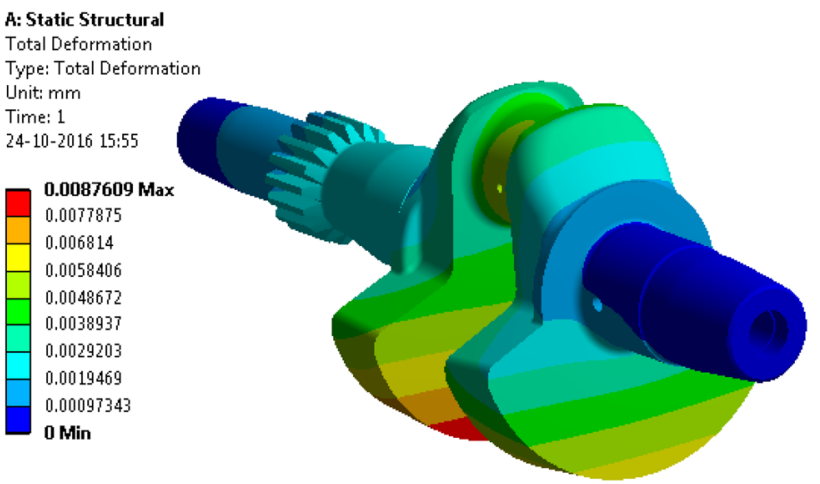

Fig. 34 Total deformation

A: Static Structural

Equivalent Stress

Type: Equivalent (von-Mises) Stress

Unit: $\mathrm{MPa}$

Time: 1

24-10-2016 15:56
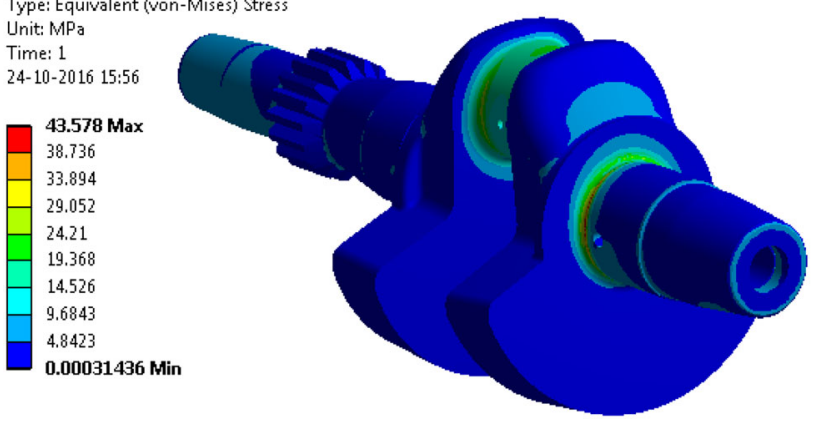

Fig. 35 Equivalent stress

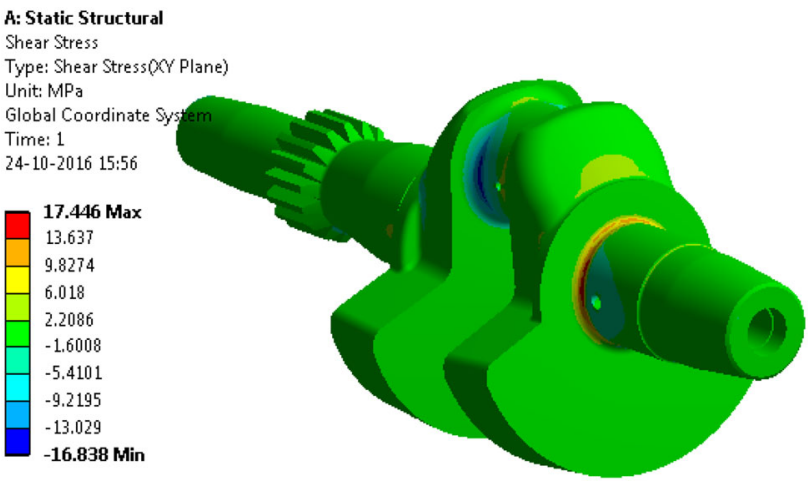

Fig. 36 Shear stress

\subsection{Modal analysis results}

See Figs. 68, 69, 70, 71, 72, 73, 74, 75, 76 and 77.

\subsection{Result of modal analysis}

See Table 6.

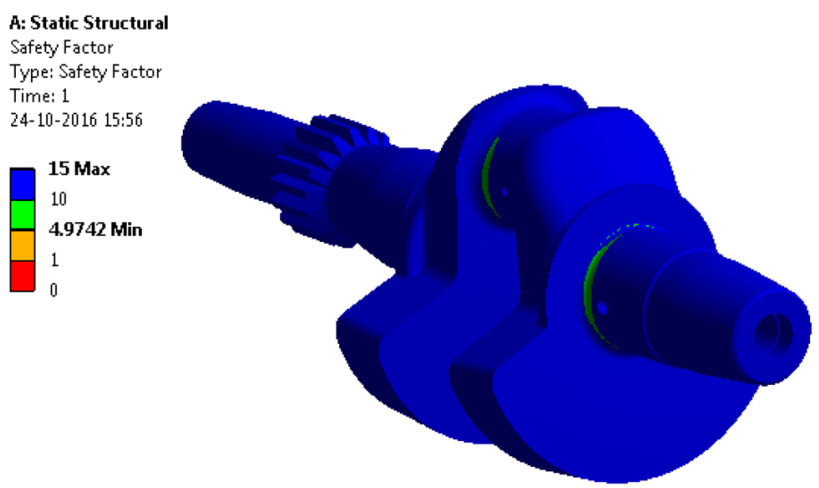

Fig. 37 Safety factor

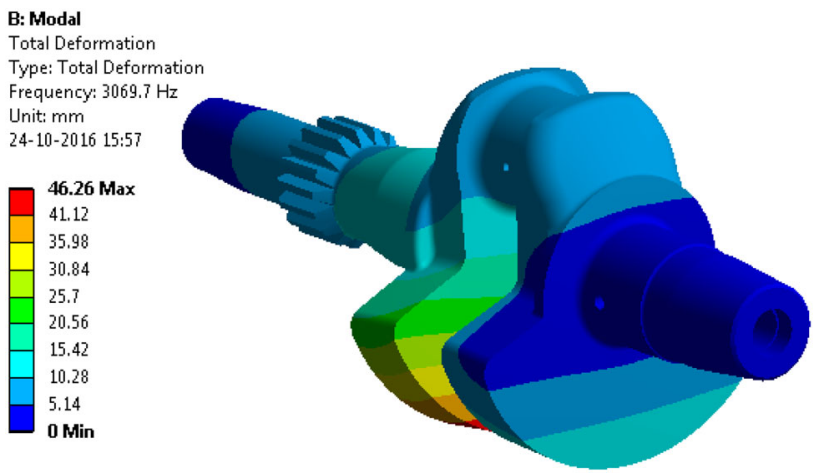

Fig. 38 First mode and deformation

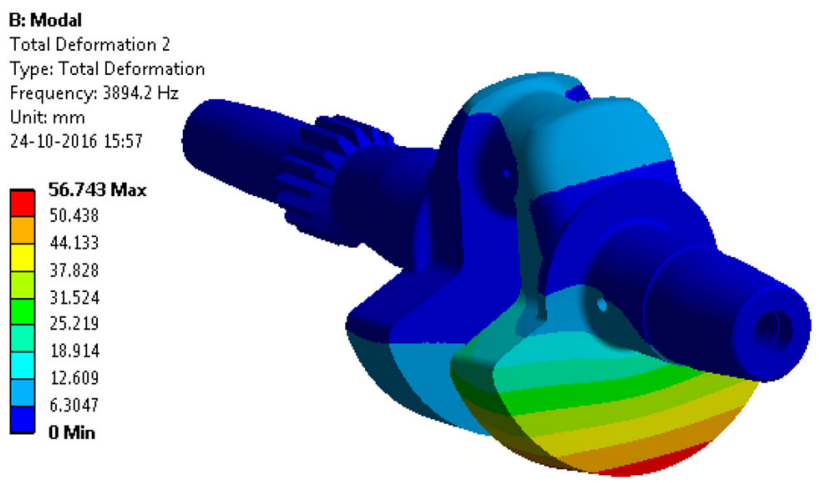

Fig. 39 Second mode and deformation

\section{Case 5: static structural and dynamic analysis of the optimized crankshaft}

The existing crankshaft was optimized by considering the geometrical changes with combination of case 1 and case 4. Figure 78 shows the optimized geometry details. 


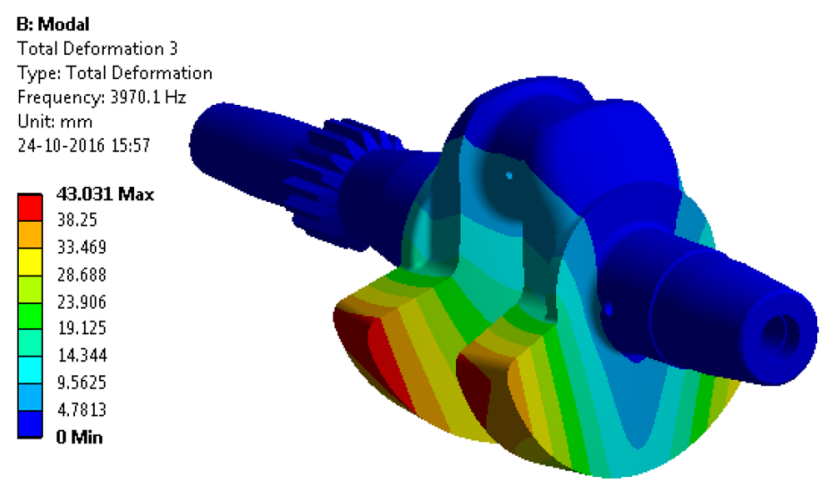

Fig. 40 Third mode and deformation

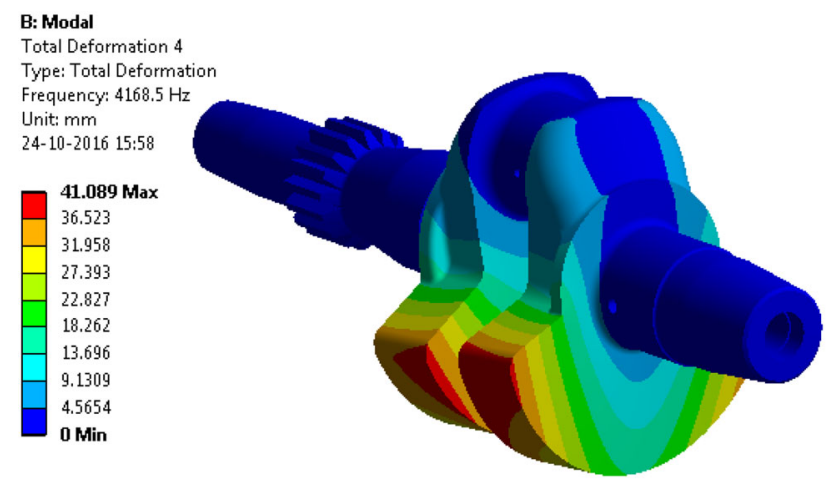

Fig. 41 Fourth mode and deformation

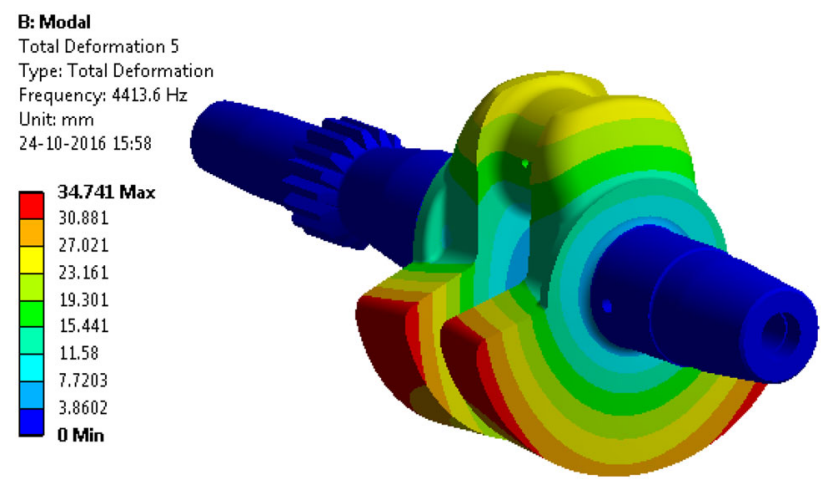

Fig. 42 Fifth mode and deformation

\subsection{Static structural analysis results}

See Figs. 79, 80, 81 and 82.

\subsection{Modal analysis results}

See Figs. 83, 84, 85, 86, 87, 88, 89, 90, 91 and 92.

\subsection{Result of modal analysis}

See Table 7.

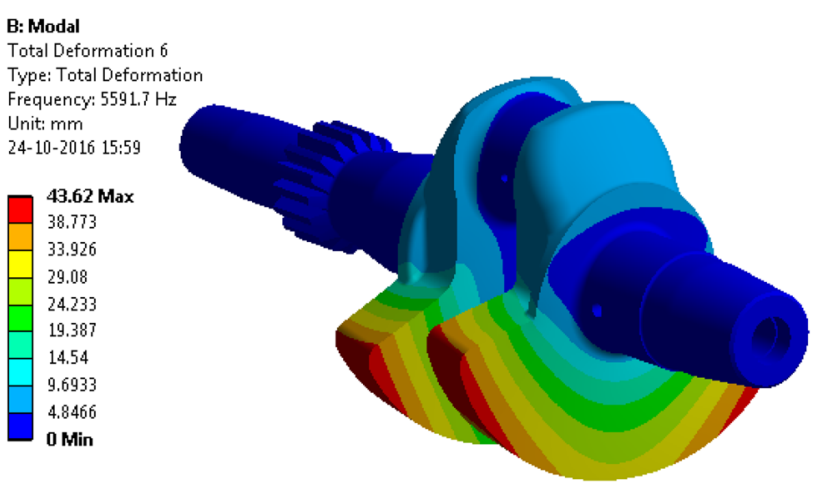

Fig. 43 Sixth mode and deformation

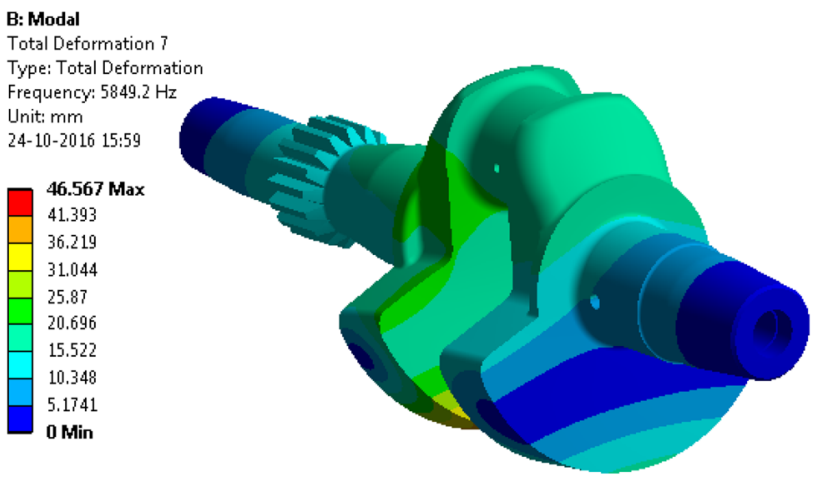

Fig. 44 Seventh mode and deformation

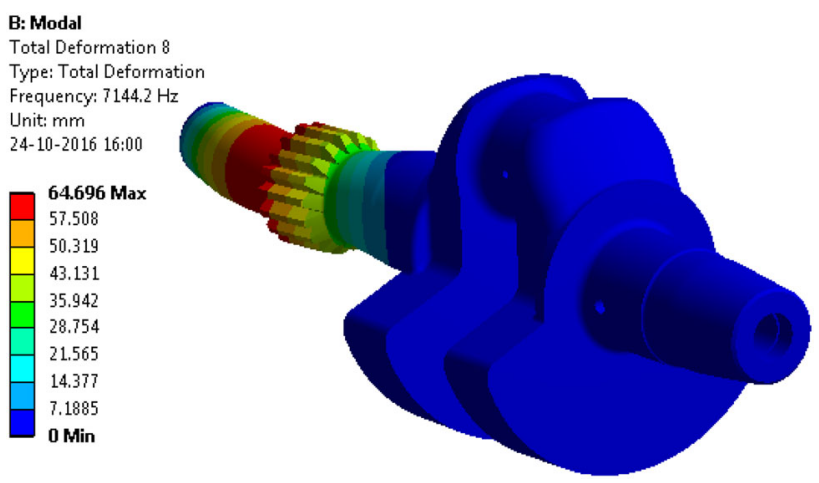

Fig. 45 Eight mode and deformation

\section{Case 6: static structural and dynamic analysis of the optimized crankshaft}

The original crankshaft was optimized geometrical changed by considered combination of case 1 , case 2 and case 4 , i.e., changed web thickness and geometry of counterweight and material removed from the crankpin. Figure 93 shows the optimized geometry details.

\subsection{Static structural analysis results}

See Figs. 94, 95, 96 and 97. 

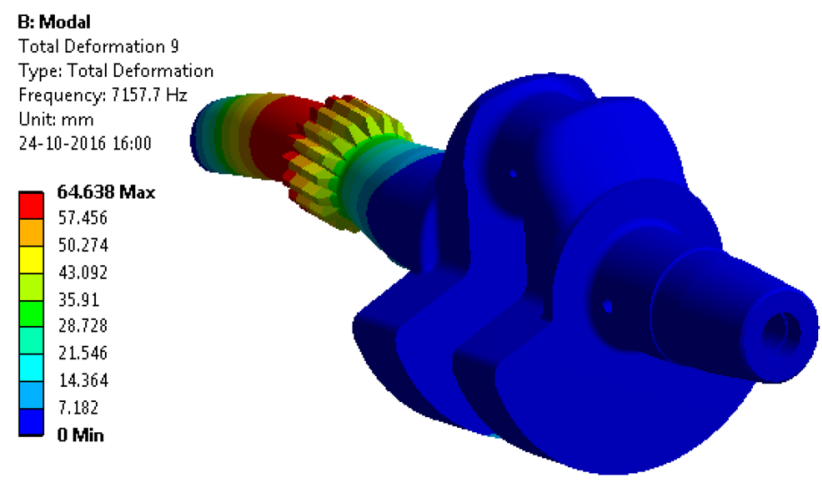

Fig. 46 Ninth mode and deformation

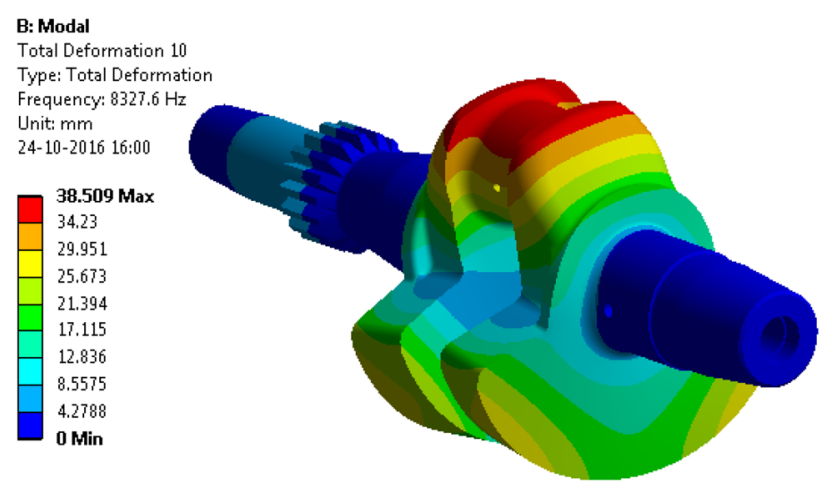

Fig. 47 Tenth mode and deformation

Table 4 Frequencies and corresponding modes

\begin{tabular}{lll}
\hline Mode & Frequency $(\mathrm{Hz})$ & Type of mode \\
\hline 1 & 3069.7 & Bending \\
2 & 3894.2 & Torsion \\
3 & 3970.1 & Bending + torsion \\
4 & 4168.5 & Torsion \\
5 & 4413.6 & Bending + torsion \\
6 & 5591.7 & Torsion \\
7 & 5849.2 & Bending + torsion \\
8 & 7144.2 & Torsion \\
9 & 7157.7 & Torsion \\
10 & 8327.6 & Bending + torsion \\
\hline
\end{tabular}
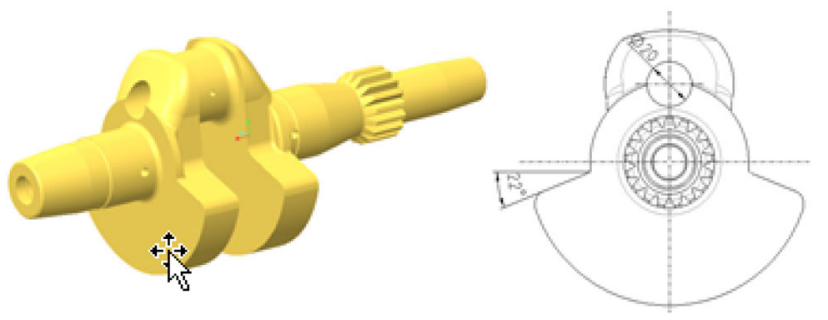

Fig. 48 Case 3-Optimized Geometry

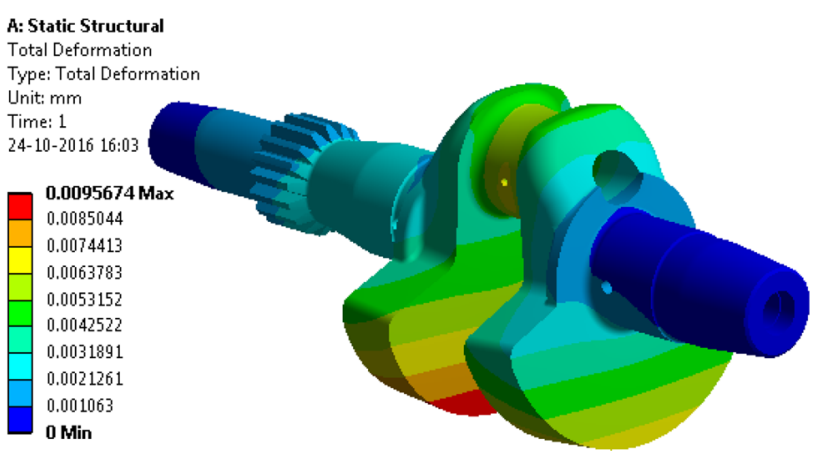

Fig. 49 Total deformation

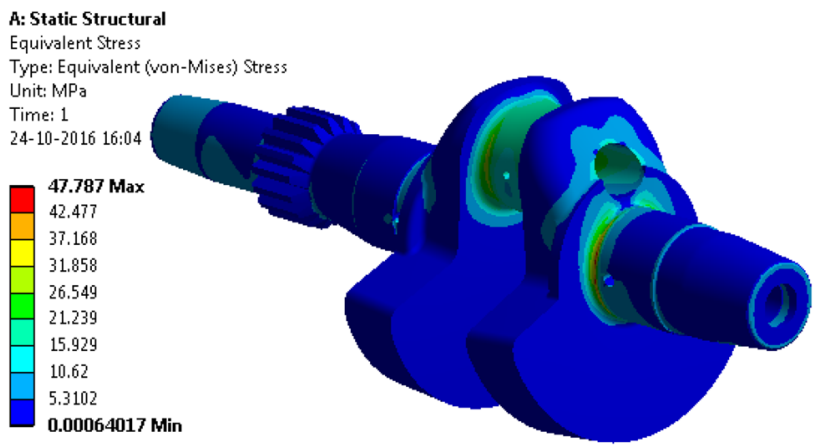

Fig. 50 Equivalent stress

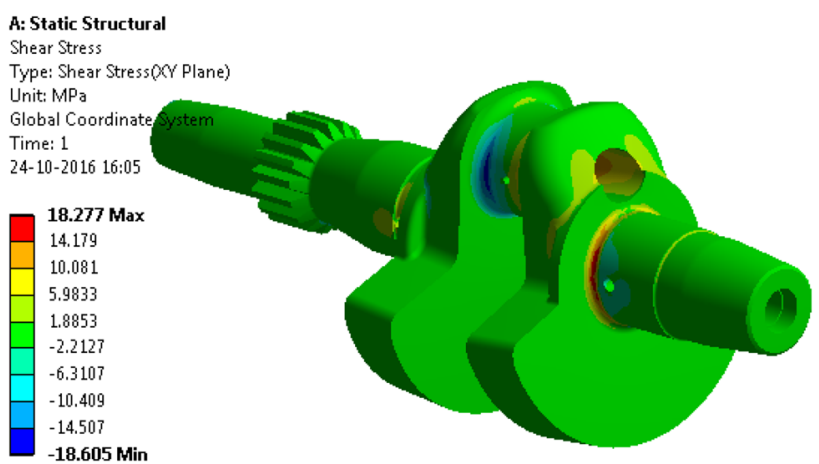

Fig. 51 Shear stress

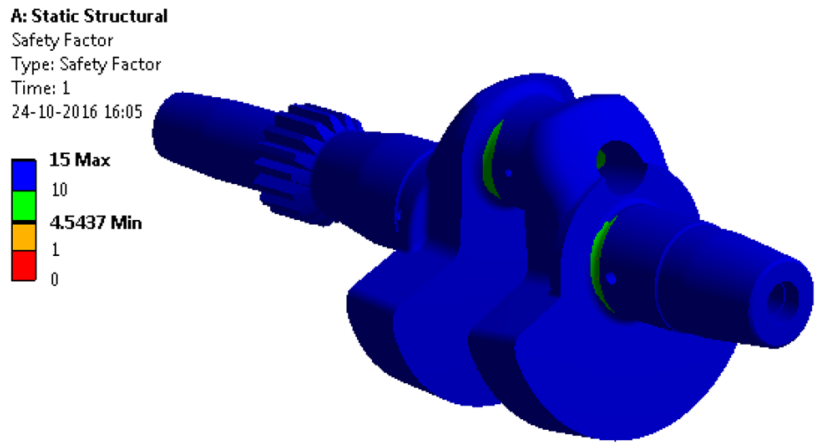

Fig. 52 Safety factor 


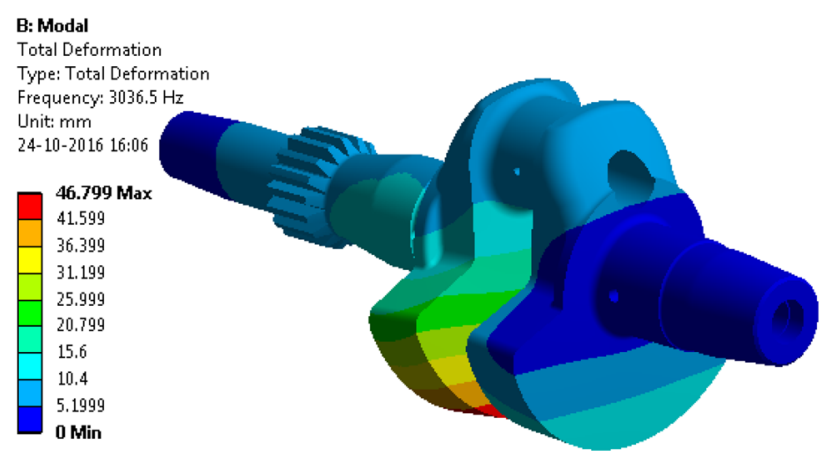

Fig. 53 First mode and deformation

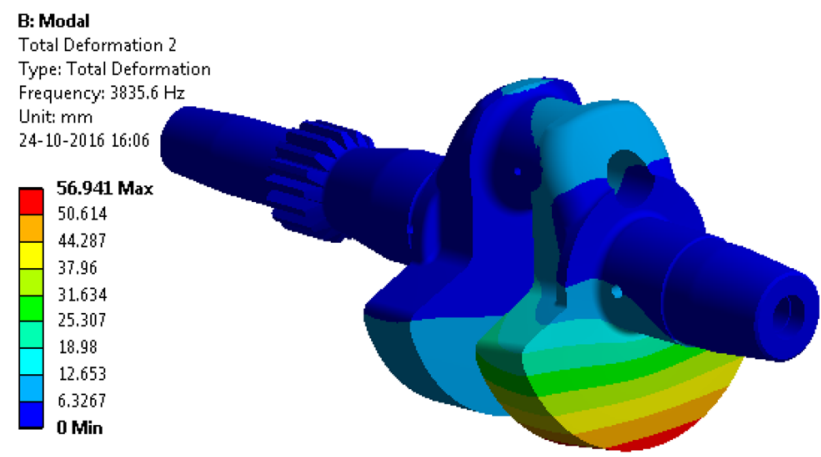

Fig. 54 Second mode and deformation

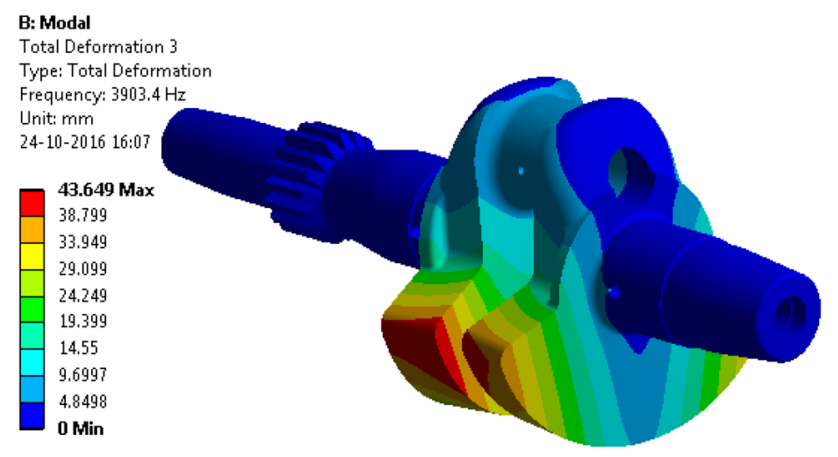

Fig. 55 Third mode and deformation

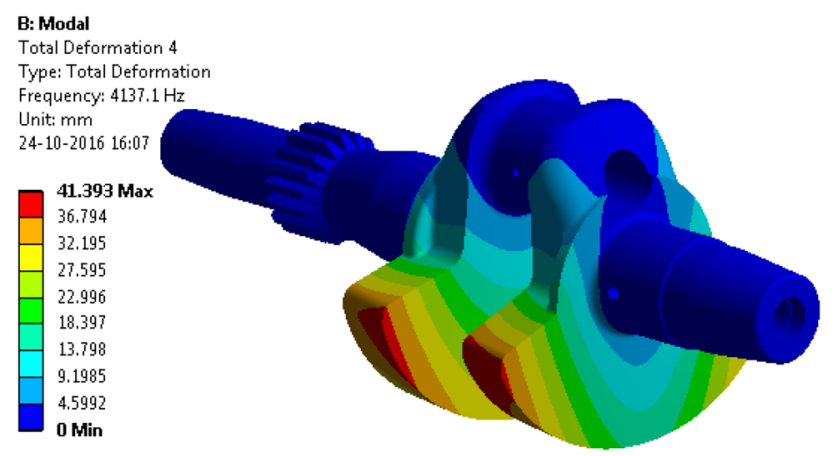

Fig. 56 Fourth mode and deformation
B: Modal

Total Deformation 5

Type: Total Deformation

Frequency: $4433.2 \mathrm{~Hz}$

Unit: $\mathrm{mm}$

34.34 Max

30.524

26.709

22.893

19.078

15.262

11.447

7.6311

3.8155

$0 \mathrm{Min}$

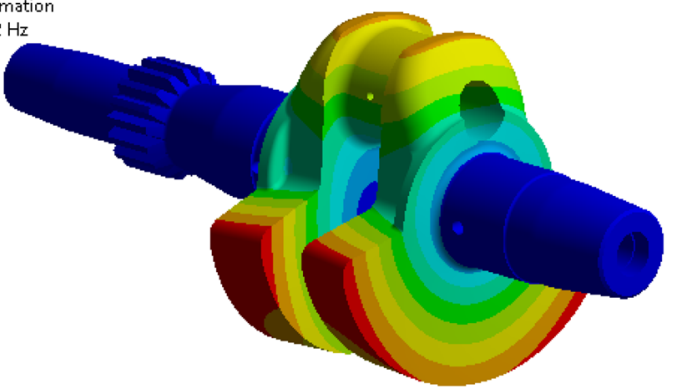

Fig. 57 Fifth mode and deformation

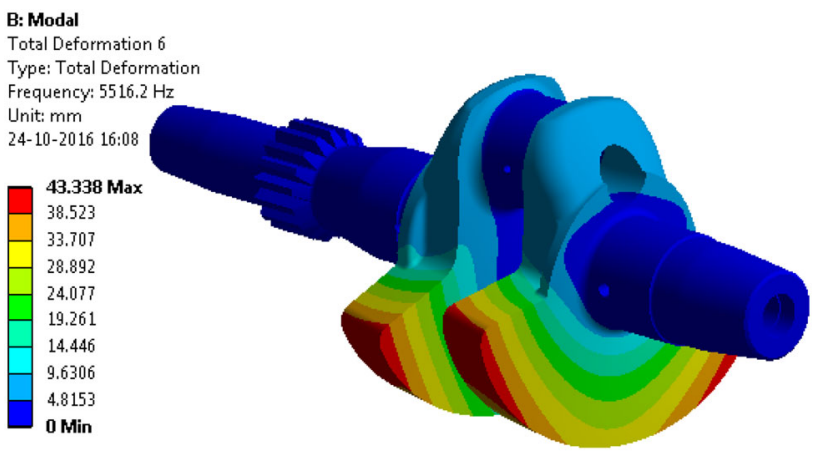

Fig. 58 Sixth mode and deformation

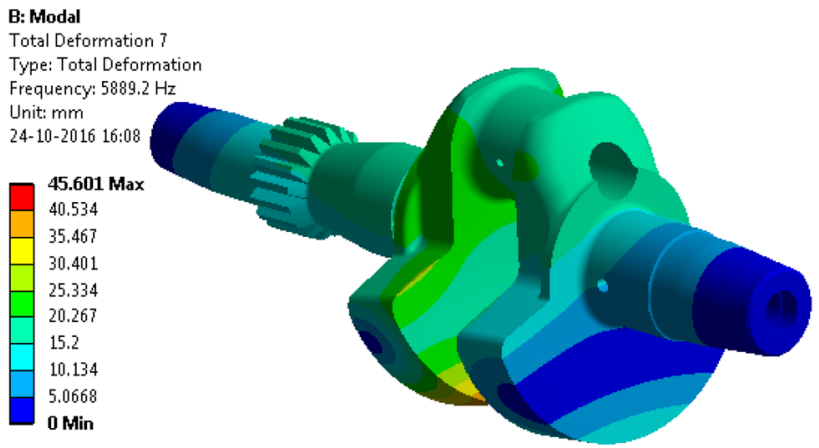

Fig. 59 Seventh mode and deformation

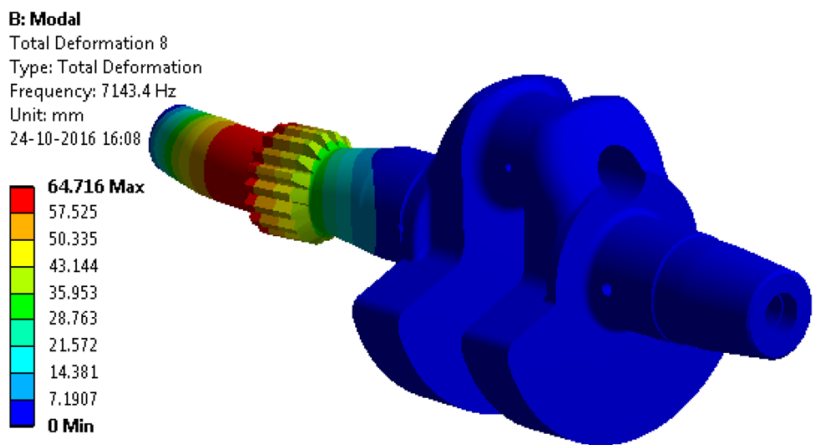

Fig. 60 Eighth mode and deformation 


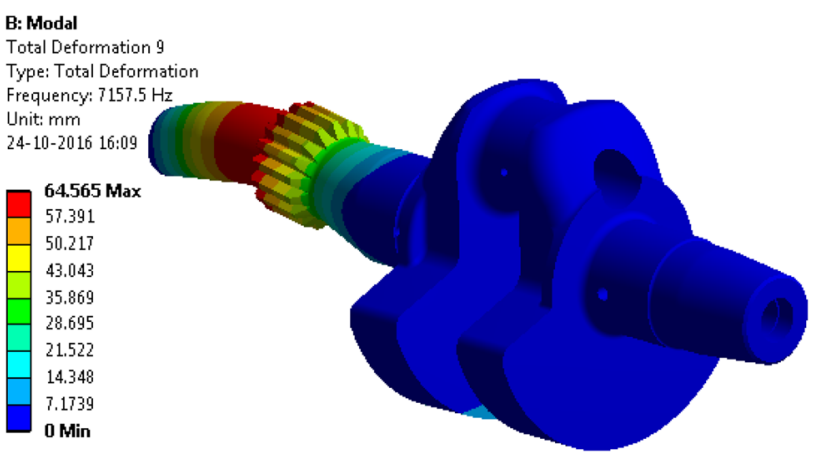

Fig. 61 Ninth mode and deformation

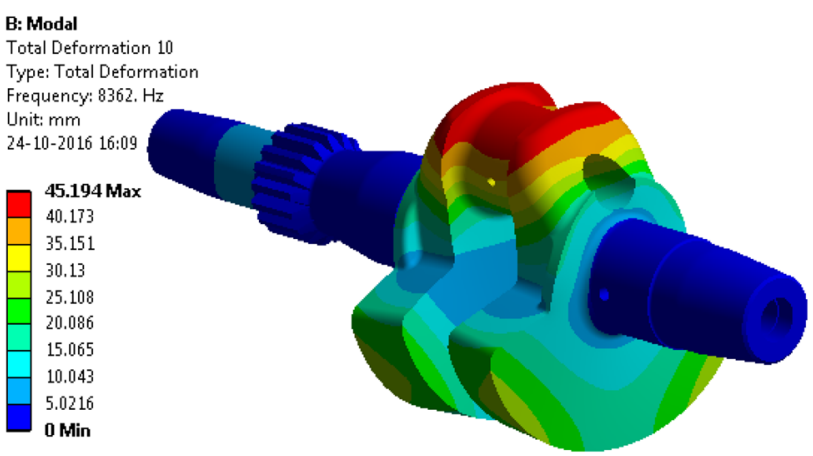

Fig. 62 Tenth mode and deformation

Table 5 Frequencies and corresponding modes

\begin{tabular}{lll}
\hline Mode & Frequency $(\mathrm{Hz})$ & Type of mode \\
\hline 1 & 3036.5 & Bending \\
2 & 3835.6 & Torsion \\
3 & 3903.4 & Bending + torsion \\
4 & 4137.1 & Torsion \\
5 & 4433.2 & Bending + torsion \\
6 & 5516.2 & Torsion \\
7 & 5889.2 & Bending + torsion \\
8 & 7143.4 & Torsion \\
9 & 7157.5 & Torsion \\
10 & 8362 & Bending + torsion \\
\hline
\end{tabular}

\subsection{Modal analysis results}

See Figs. 98, 99, 100, 101, 102, 103, 104, 105, 106 and 107.

\subsection{Result of modal analysis}

See Table 8.

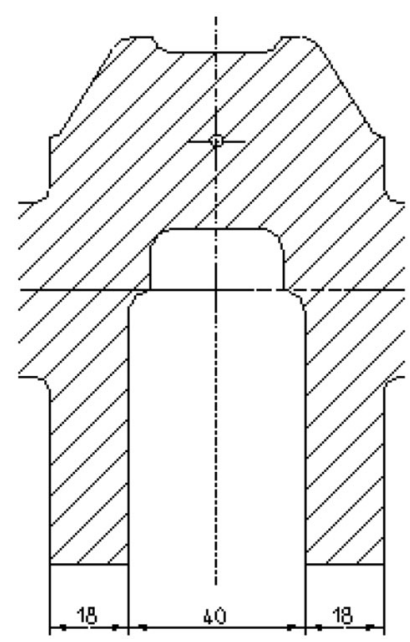

Fig. 63 Case 4: optimized Geometry

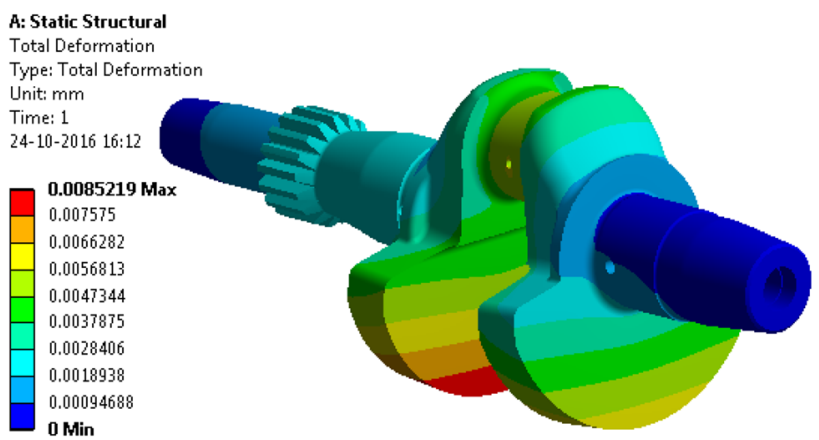

Fig. 64 Total deformation

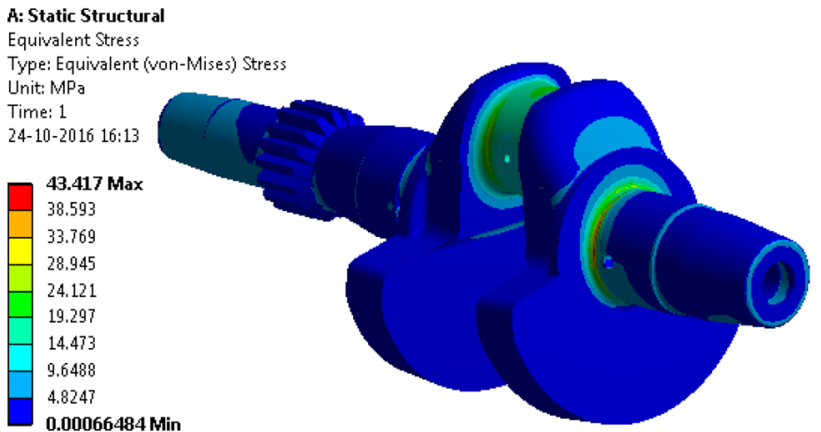

Fig. 65 Equivalent stress

\section{Conclusion}

The optimized crankshaft cases results were compared with the benchmark crankshaft results and material allowable stress limits. All the optimized crankshaft cases are statically safe, but some of the optimized crankshaft cases were not safe in the dynamic condition [24]. The overview of the results is listed in Table 9. 


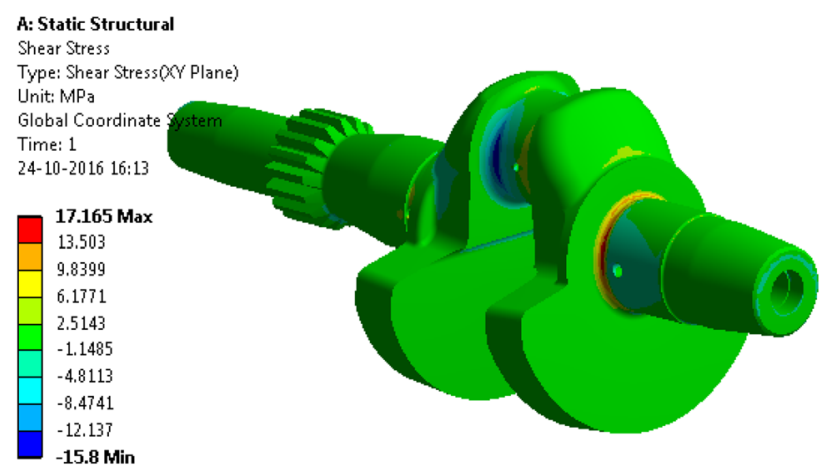

Fig. 66 Shear stress

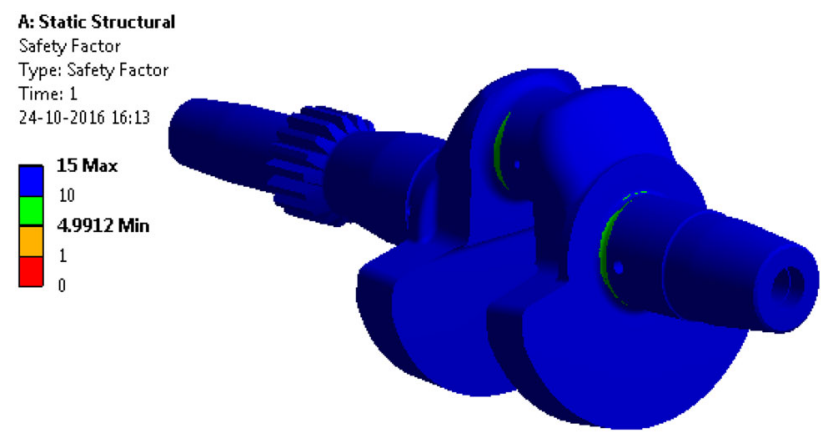

Fig. 67 Safety factor

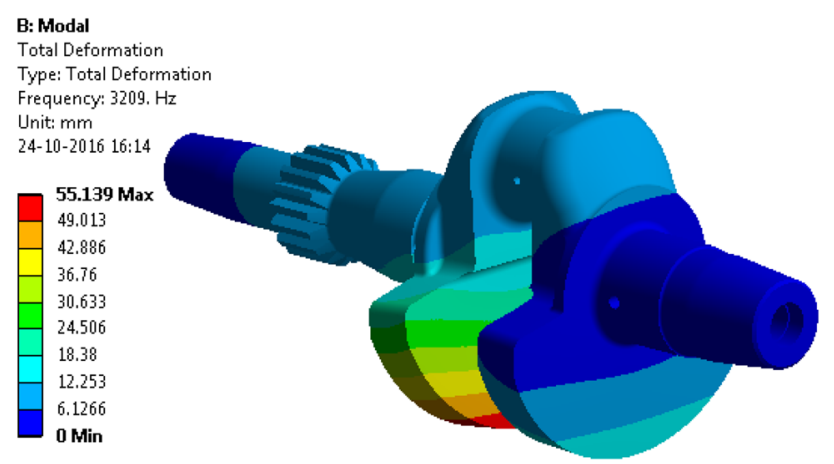

Fig. 68 First mode and deformation

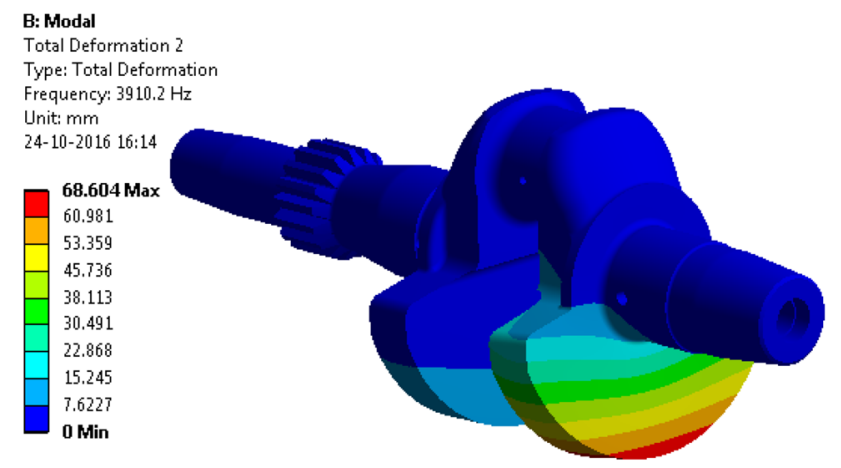

Fig. 69 Second mode and deformation

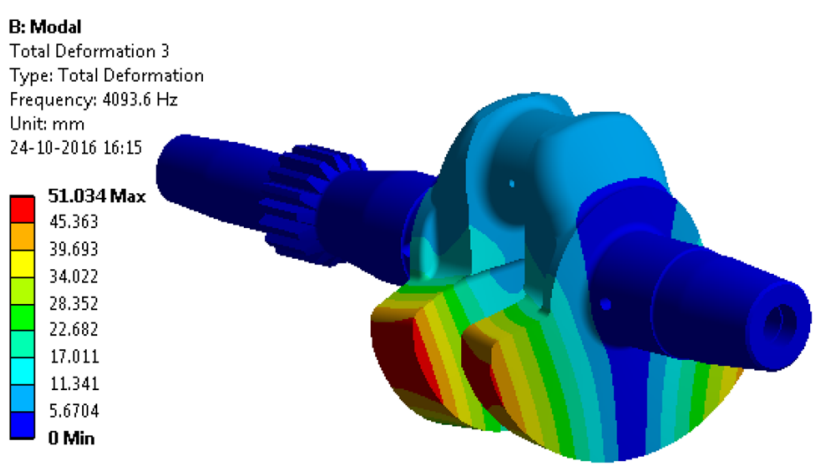

Fig. 70 Third mode and deformation

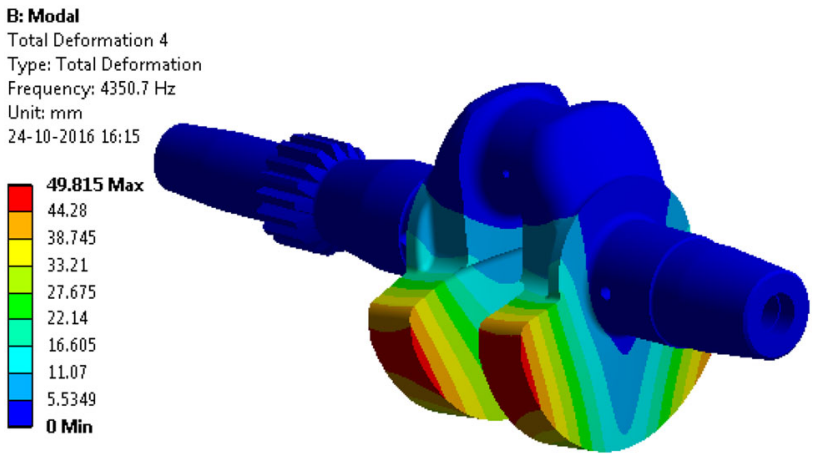

Fig. 71 Fourth mode and deformation

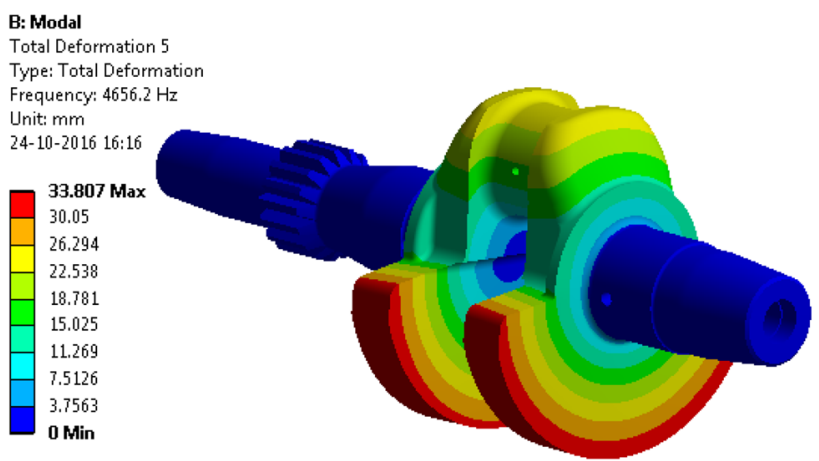

Fig. 72 Fifth mode and deformation

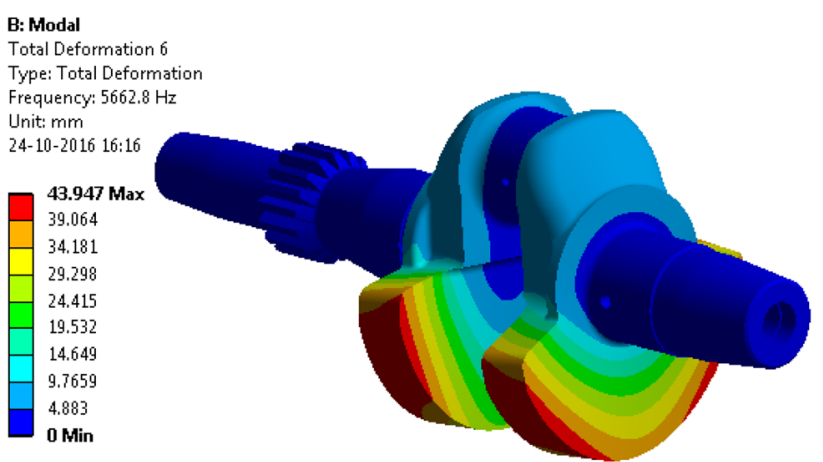

Fig. 73 Sixth mode and deformation 


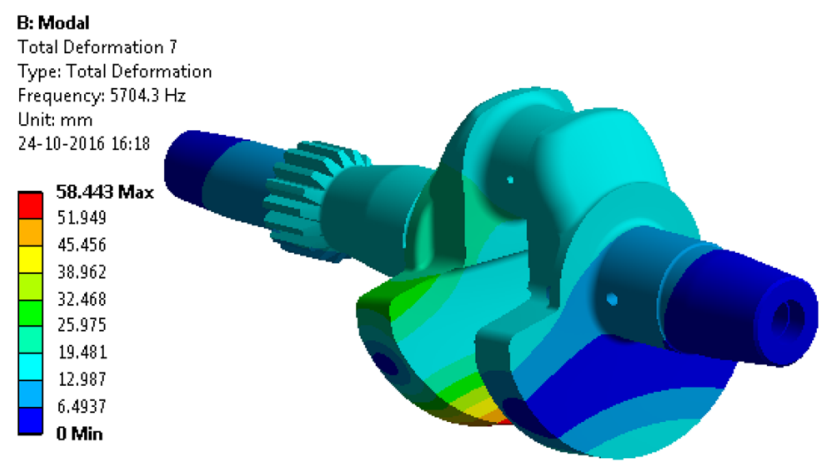

Fig. 74 Seventh mode and deformation

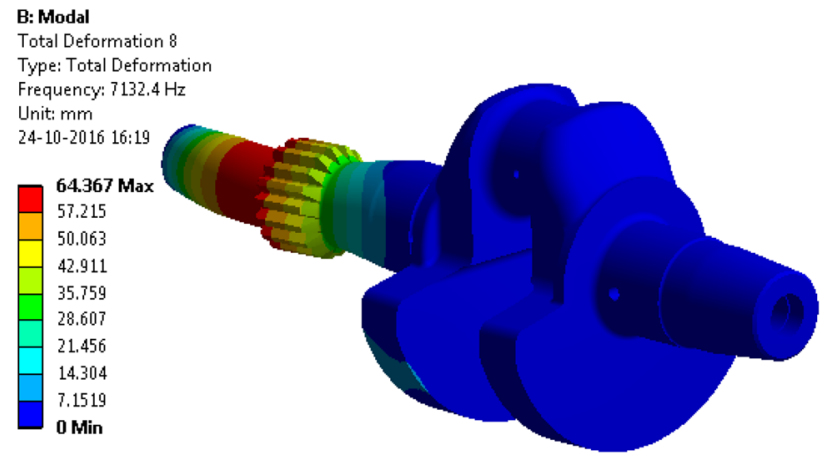

Fig. 75 Eighth mode and deformation

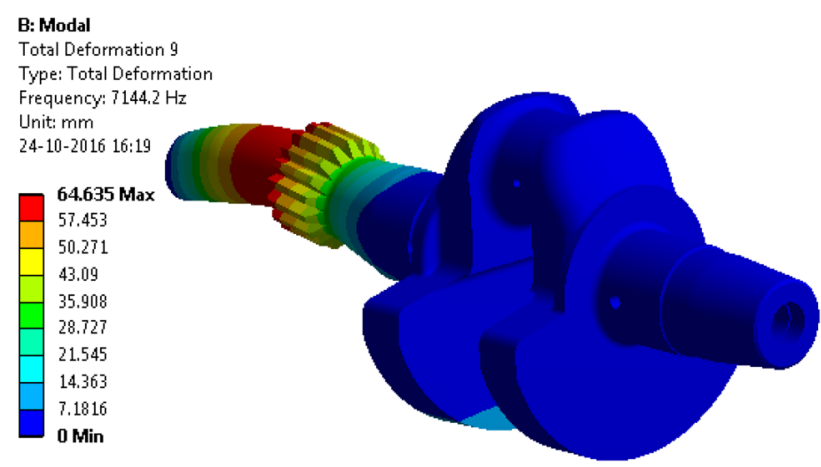

Fig. 76 Ninth mode and deformation

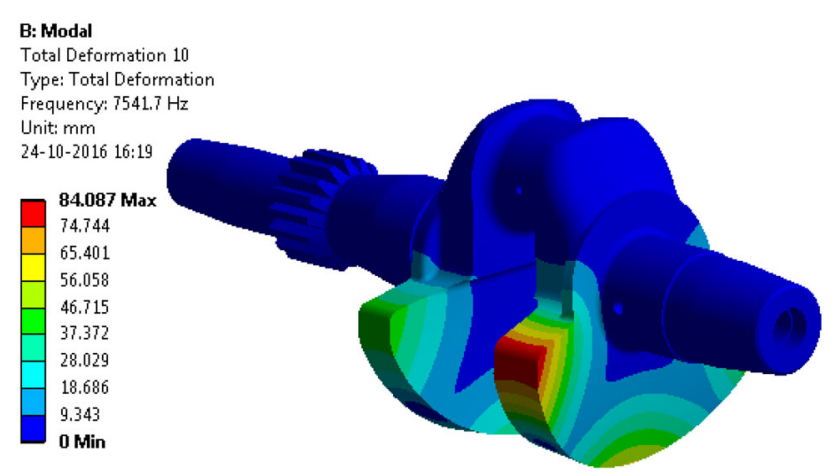

Fig. 77 Tenth mode and deformation
Table 6 Frequencies and corresponding modes

\begin{tabular}{lll}
\hline Mode & Frequency $(\mathrm{Hz})$ & Type of mode \\
\hline 1 & 3209 & Bending \\
2 & 3910.2 & Torsion \\
3 & 4093.5 & Bending + torsion \\
4 & 4350.7 & Torsion \\
5 & 4656.2 & Bending + torsion \\
6 & 5662.8 & Torsion \\
7 & 5704.3 & Bending + torsion \\
8 & 7132.4 & Torsion \\
9 & 7144.2 & Torsion \\
10 & 7541.7 & Bending + torsion \\
\hline
\end{tabular}

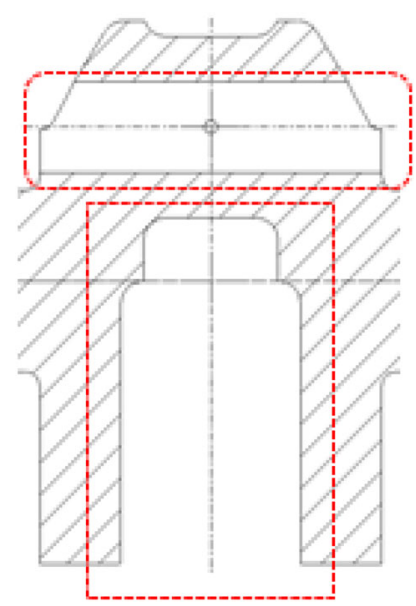

Fig. 78 Case 5: optimized geometry

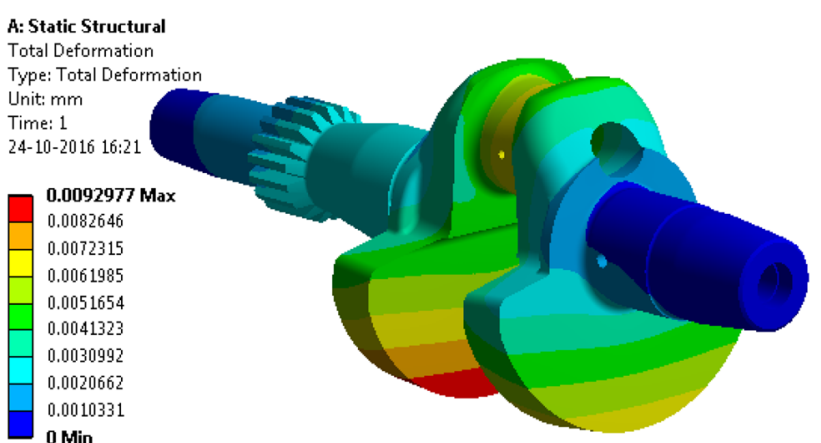

Fig. 79 Total deformation

In dynamic cases, the percentage of deviation in the frequency of optimized cases of the crankshaft when compared with frequencies of the existing crankshaft was not more than $10 \%$ of the existing crankshaft results. The overall percentage in the frequency with existing crankshaft design is listed in Table 10. 


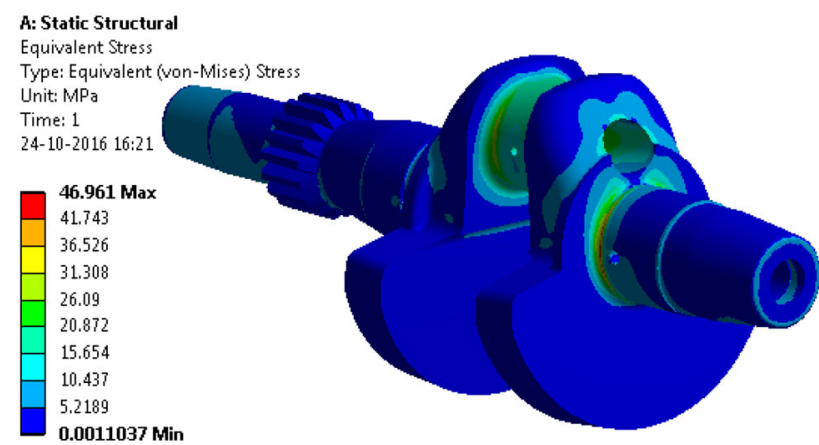

Fig. 80 Equivalent stress

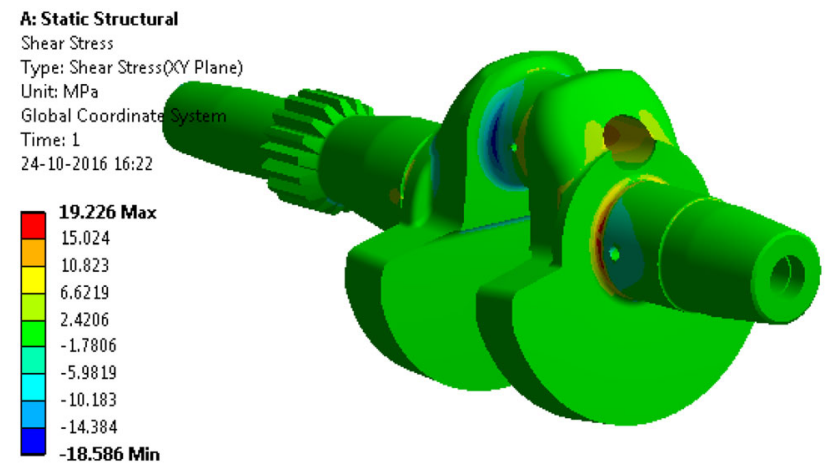

Fig. 81 Shear stress

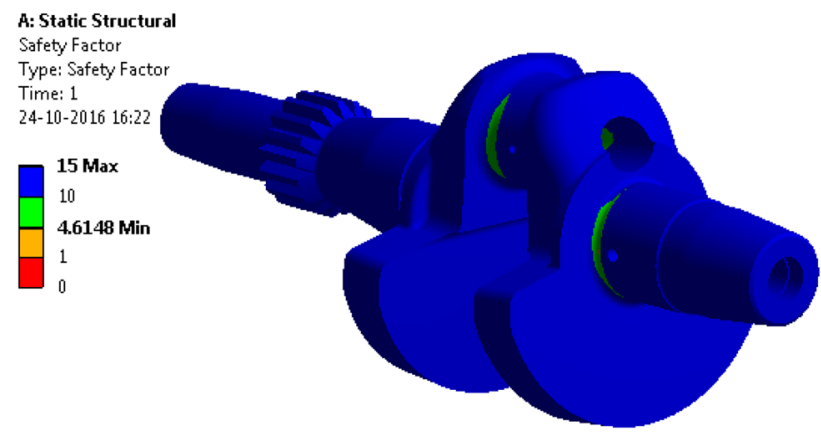

Fig. 82 Safety factor

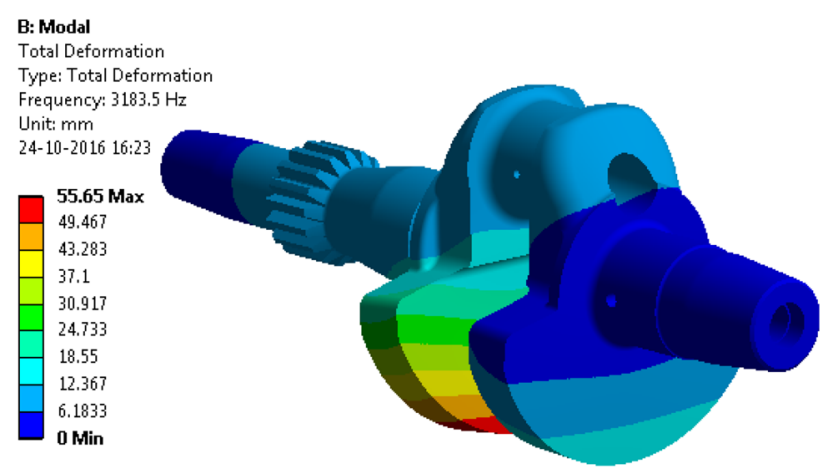

Fig. 83 First mode and deformation

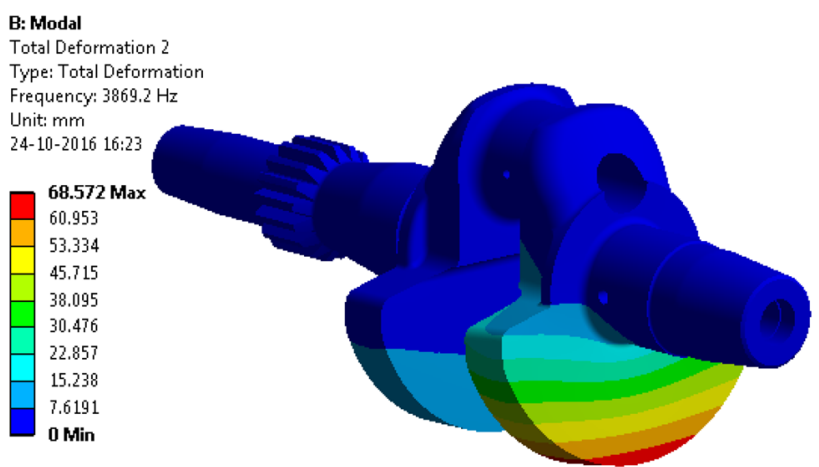

Fig. 84 Second mode and deformation

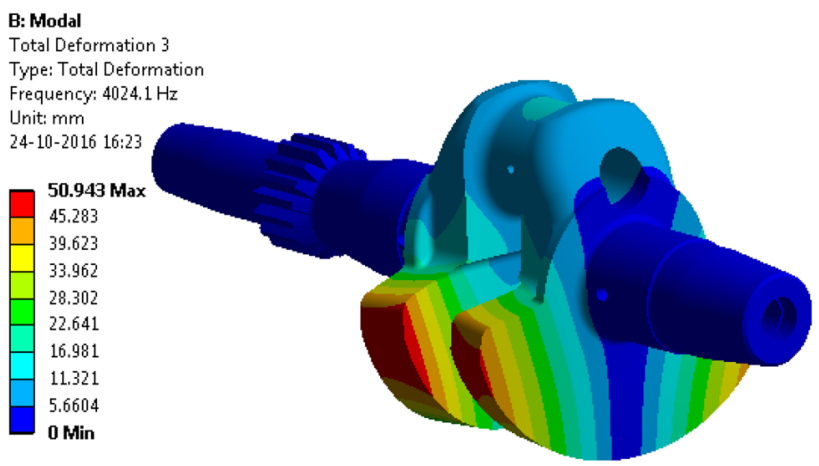

Fig. 85 Third mode and deformation

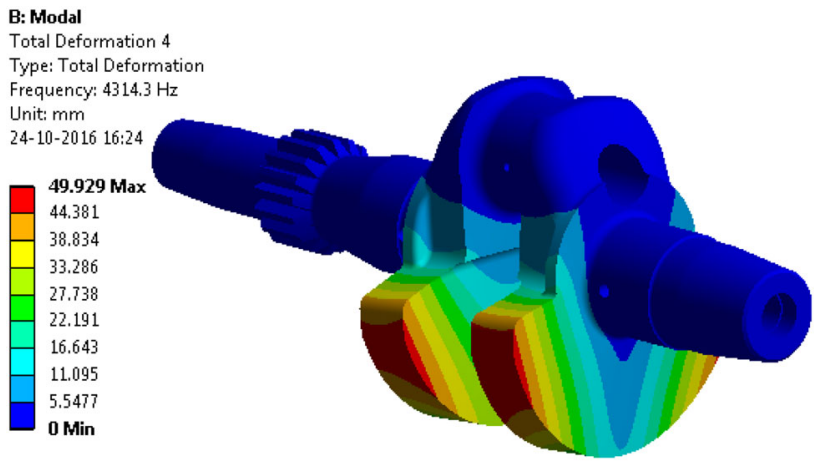

Fig. 86 Fourth mode and deformation

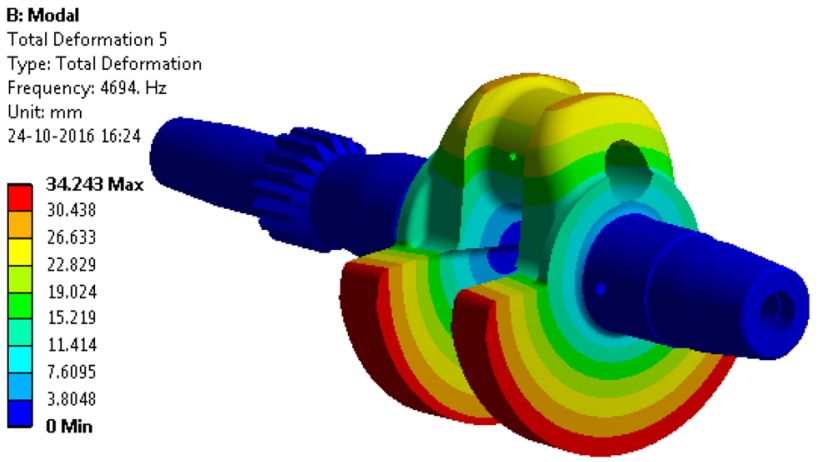

Fig. 87 Fifth mode and deformation 


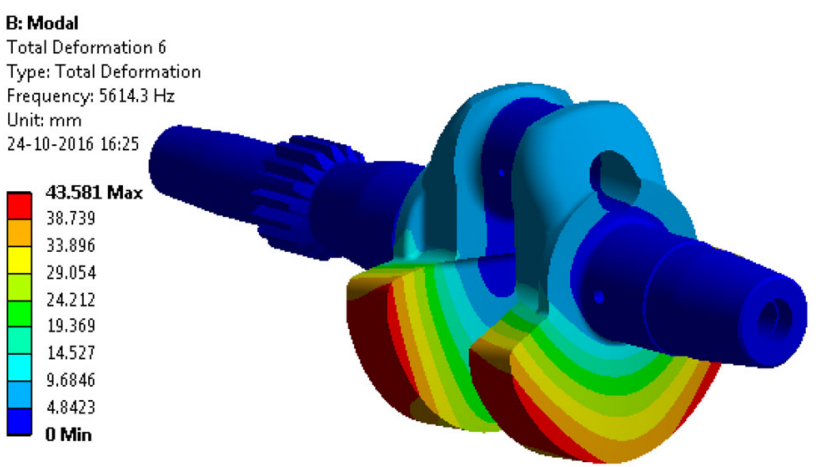

Fig. 88 Sixth mode and deformation

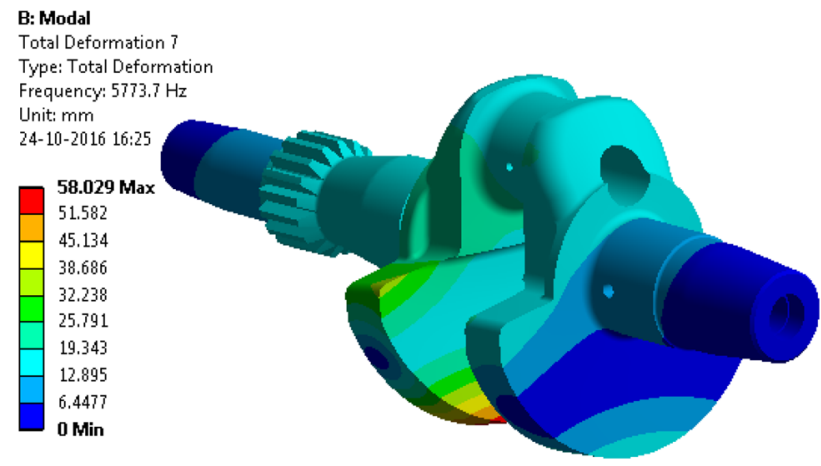

Fig. 89 Seventh mode and deformation

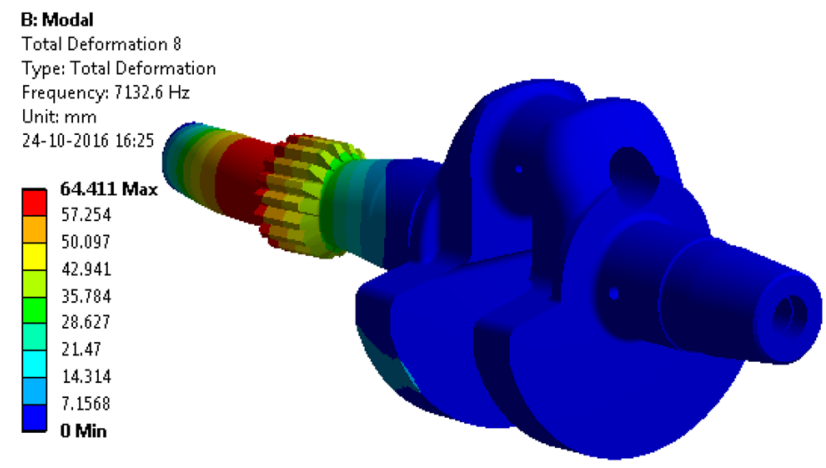

Fig. 90 Eighth mode and deformation

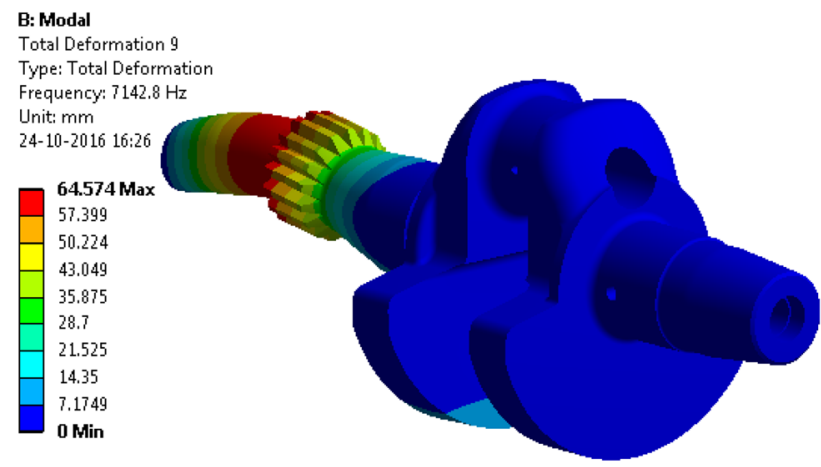

Fig. 91 Ninth mode and deformation

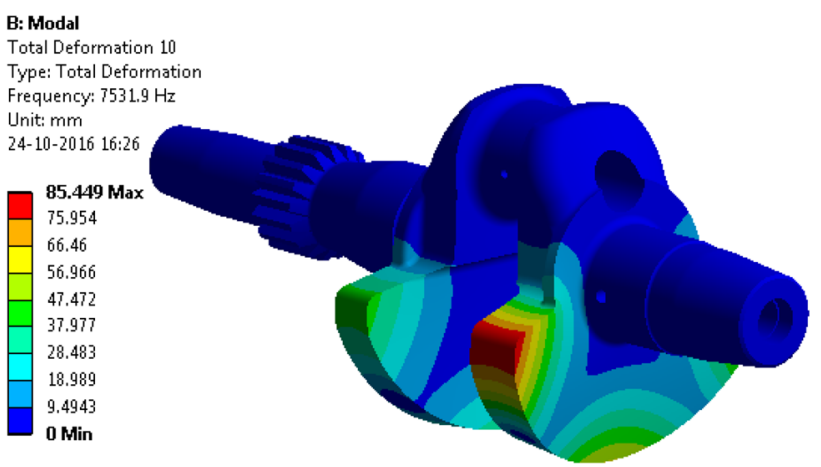

Fig. 92 Tenth mode and deformation

Table 7 Frequencies and corresponding modes

\begin{tabular}{lll}
\hline Mode & Frequency $(\mathrm{Hz})$ & Type of mode \\
\hline 1 & 3183.5 & Bending \\
2 & 3869.2 & Torsion \\
3 & 4024.1 & Bending + torsion \\
4 & 4314.3 & Torsion \\
5 & 4694 & Bending + torsion \\
6 & 5614.3 & Torsion \\
7 & 5773.7 & Bending + torsion \\
8 & 7132.6 & Torsion \\
9 & 7142.8 & Torsion \\
10 & 7531.9 & Bending + torsion
\end{tabular}

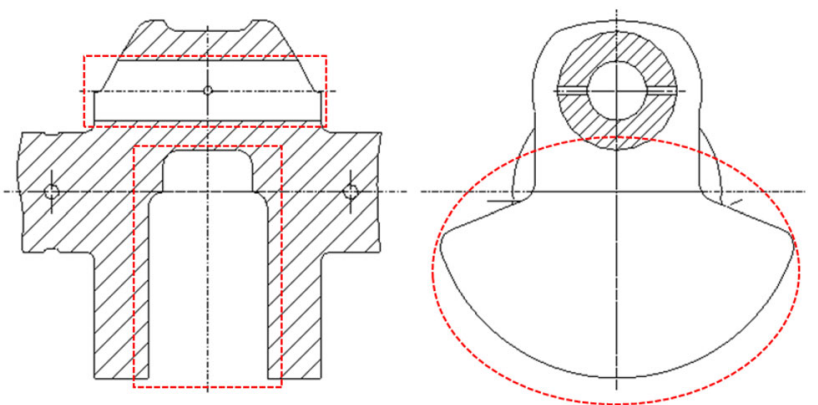

Fig. 93 Case 6: optimized geometry

In dynamic analysis considering the $\pm 10 \%$ of frequency deviation criteria with existing design criteria, the dynamic results of all the optimized cases are evaluated and validated. Hence considering $\pm 10 \%$ frequency deviation criteria case 1 , case 2 , case 3 , case 4 and case 5 , the optimized crankshaft design in dynamic loading conditions is safe, but case 6 optimized crankshaft design failed under dynamic loading condition. In Table 11 "SAFE" shows that $10 \%$ frequency deviation criteria are satisfied and "UNSAFE" shows that $10 \%$ frequency deviation criteria are not satisfied. The overview of $\pm 10 \%$ frequency deviation criteria results are shown in Table 11. 


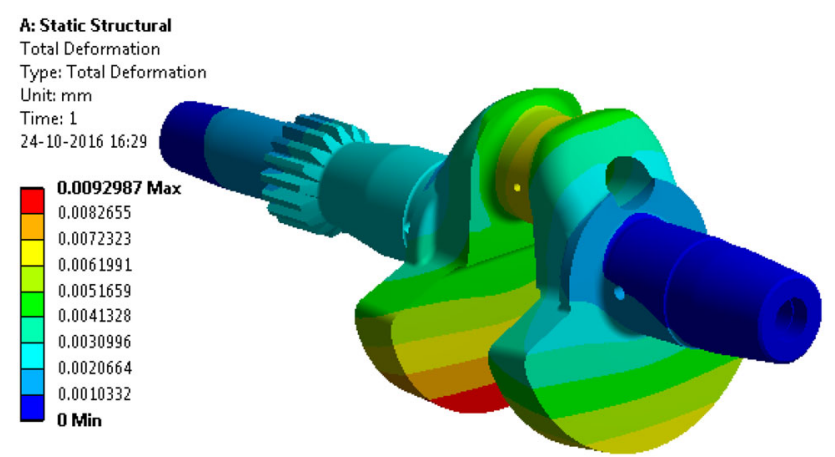

Fig. 94 Total deformation

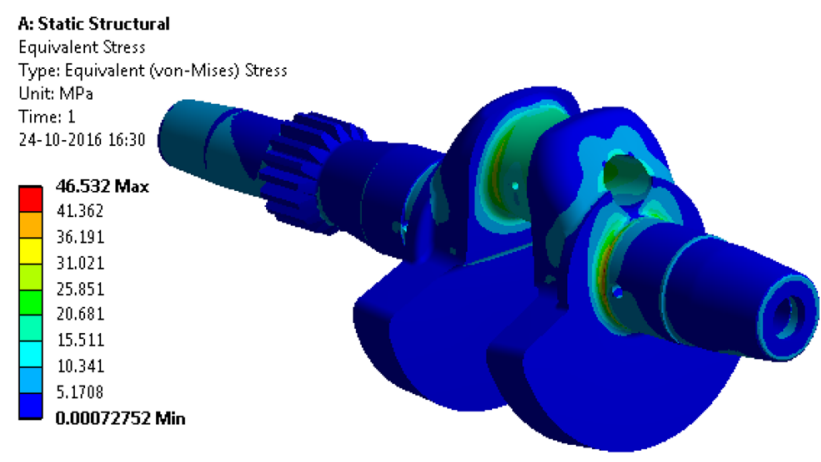

Fig. 95 Equivalent stress

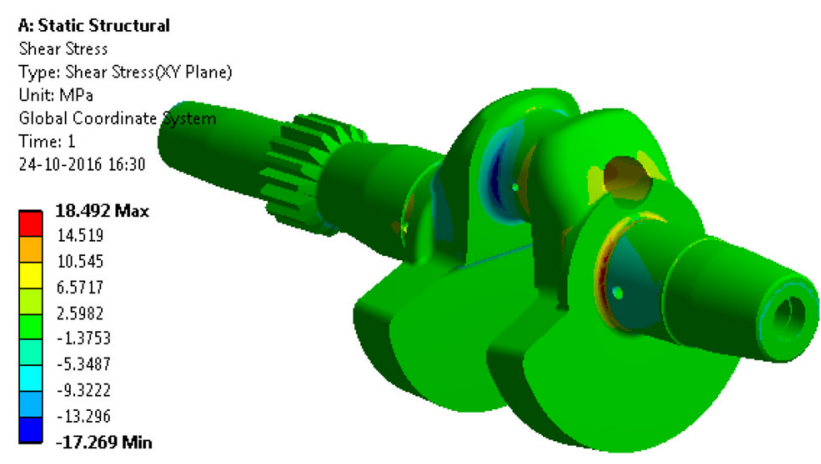

Fig. 96 Shear stress

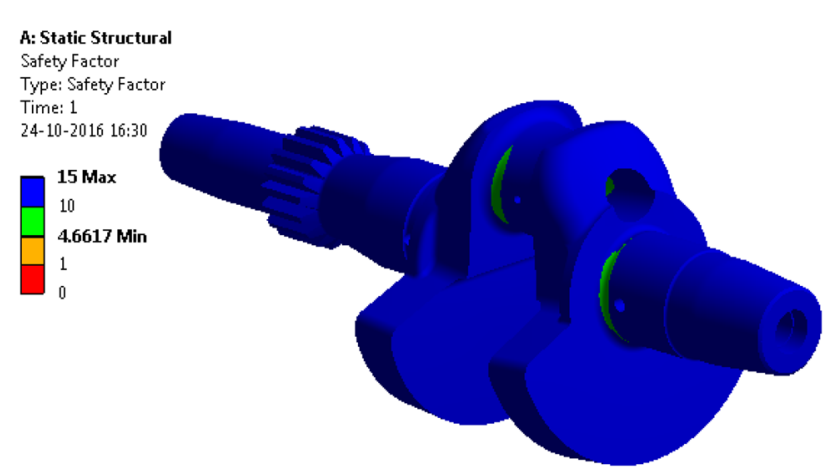

Fig. 97 Safety factor

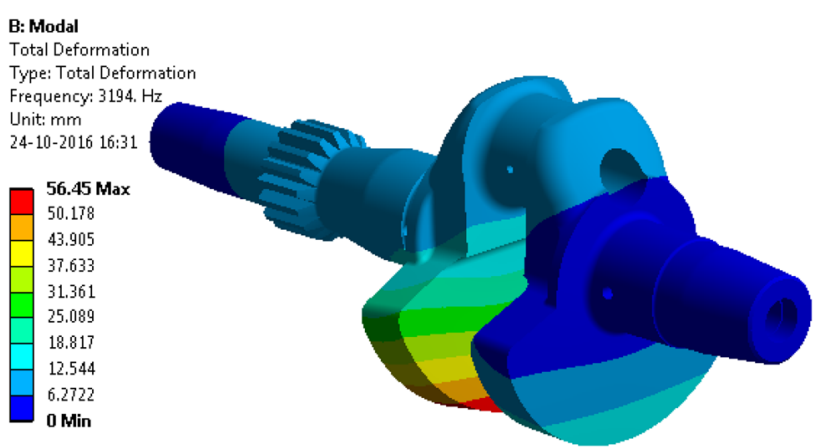

Fig. 98 First mode and deformation

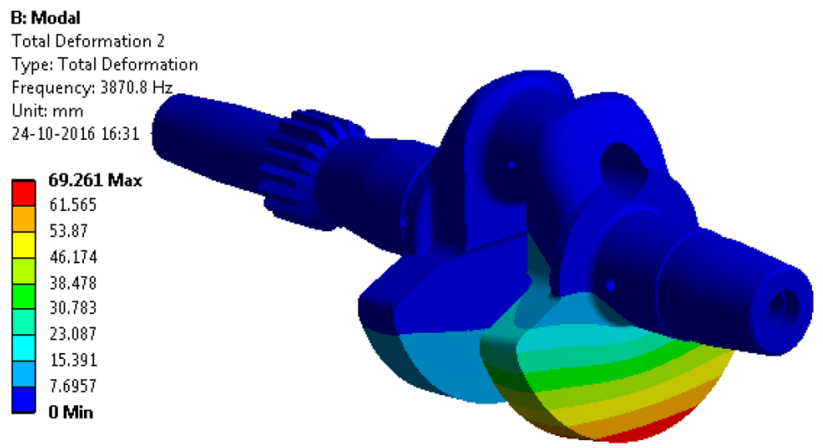

Fig. 99 Second mode and deformation

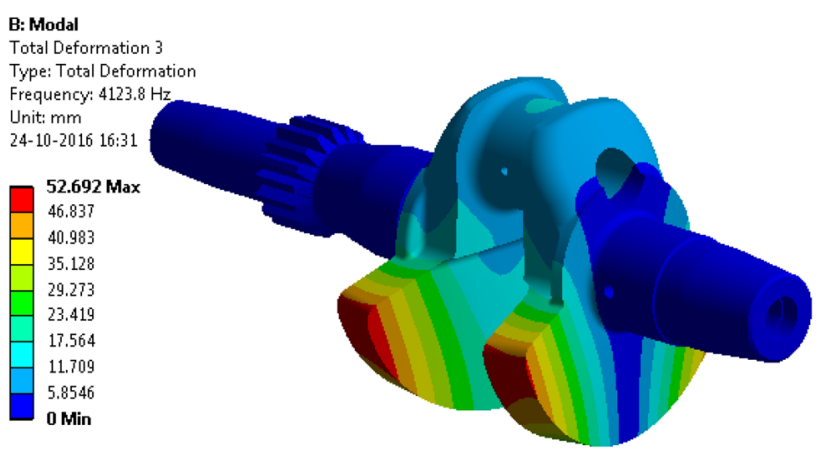

Fig. 100 Third mode and deformation

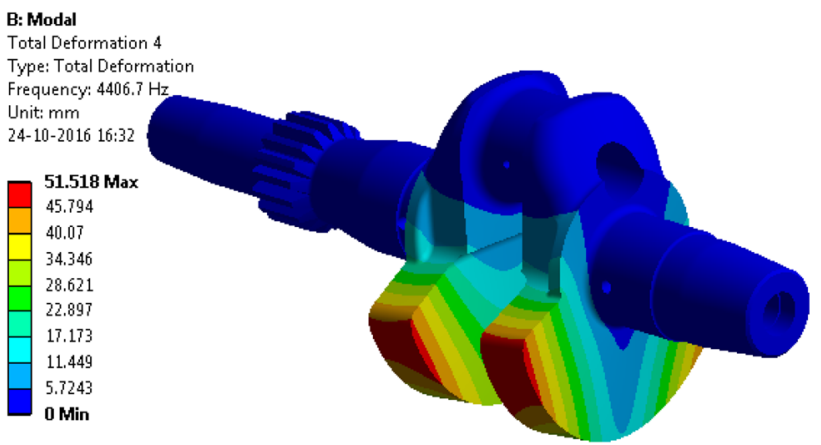

Fig. 101 Fourth mode and deformation 


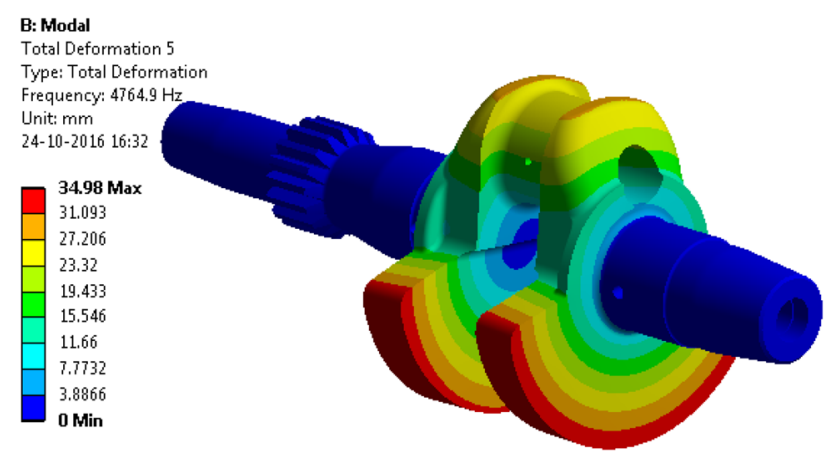

Fig. 102 Fifth mode and deformation

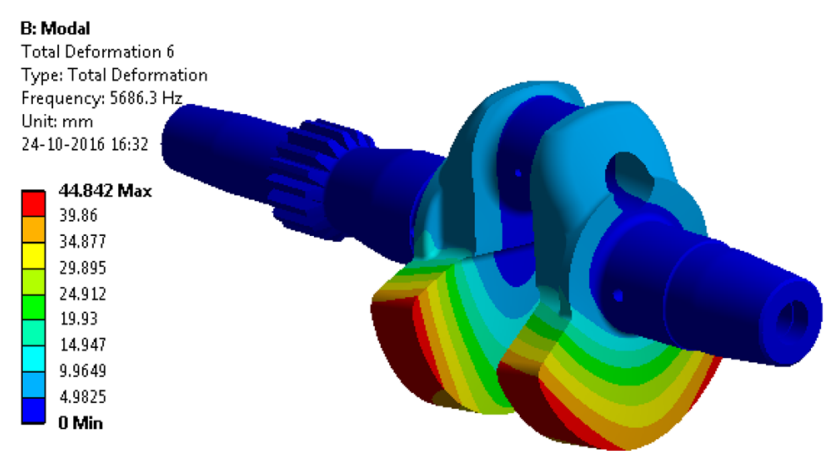

Fig. 103 Sixth mode and deformation

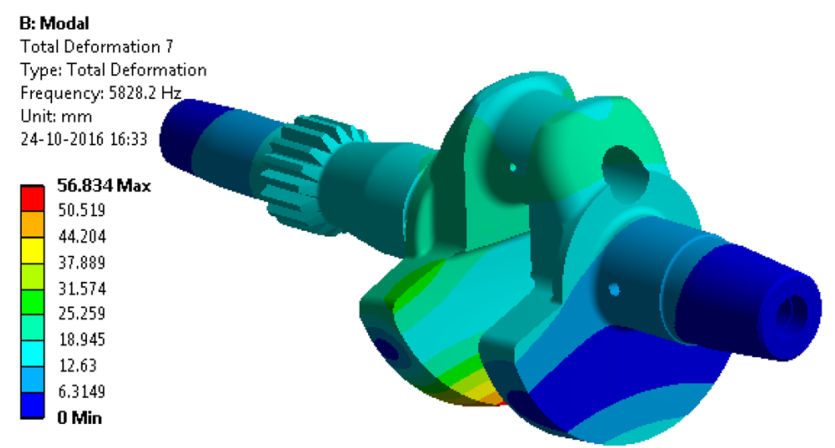

Fig. 104 Seventh mode and deformation

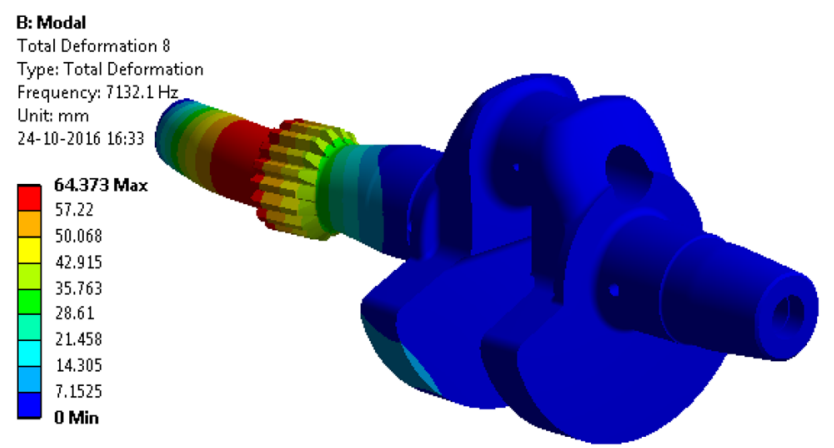

Fig. 105 Eighth mode and deformation

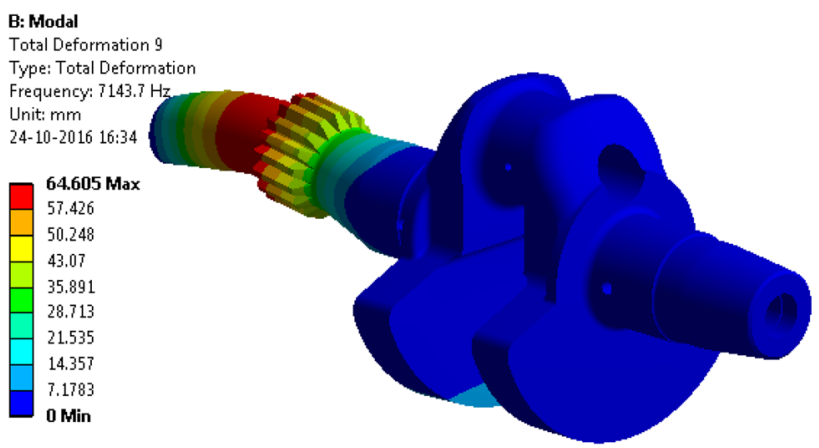

Fig. 106 Ninth mode and deformation

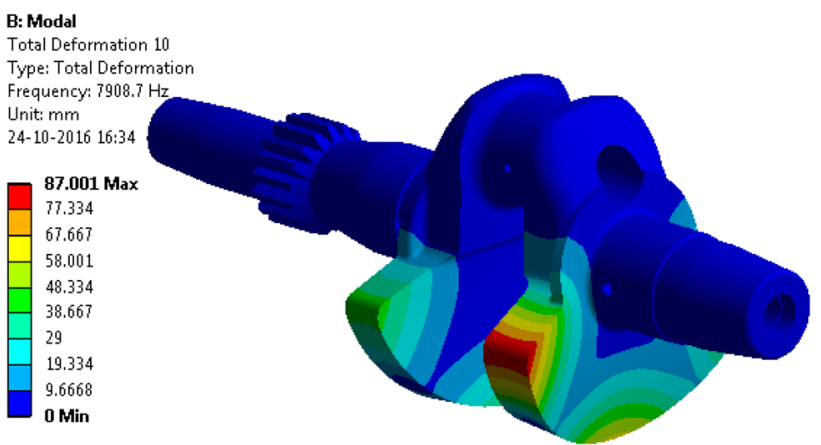

Fig. 107 Tenth mode and deformation

Table 8 Frequencies and corresponding modes

\begin{tabular}{lll}
\hline Mode & Frequency $(\mathrm{Hz})$ & Type of mode \\
\hline 1 & 3194 & Bending \\
2 & 3870.8 & Torsion \\
3 & 4123.8 & Bending + torsion \\
4 & 4406.7 & Torsion \\
5 & 4764.9 & Bending + torsion \\
6 & 5686.3 & Torsion \\
7 & 5828.2 & Bending + torsion \\
8 & 7132.1 & Torsion \\
9 & 7143.7 & Torsion \\
10 & 7908.7 & Bending + torsion \\
\hline
\end{tabular}

In dynamic analysis considering the $\pm 5 \%$ of frequency deviation criteria with existing design criteria, the dynamic results of all the optimized cases are evaluated and validated. Hence considering $\pm 5 \%$ frequency deviation criteria, case 1 , case 2, case 3 and case 6 with optimized crankshaft design in dynamic loading conditions are safe, but case 4 and case 5 with optimized crankshaft design failed under dynamic loading condition. In Table 12 "SAFE" shows that $5 \%$ frequency deviation criteria are satisfied and "UNSAFE" shows that 5\% frequency 
Table 9 Static analysis and dynamic analysis FEA results

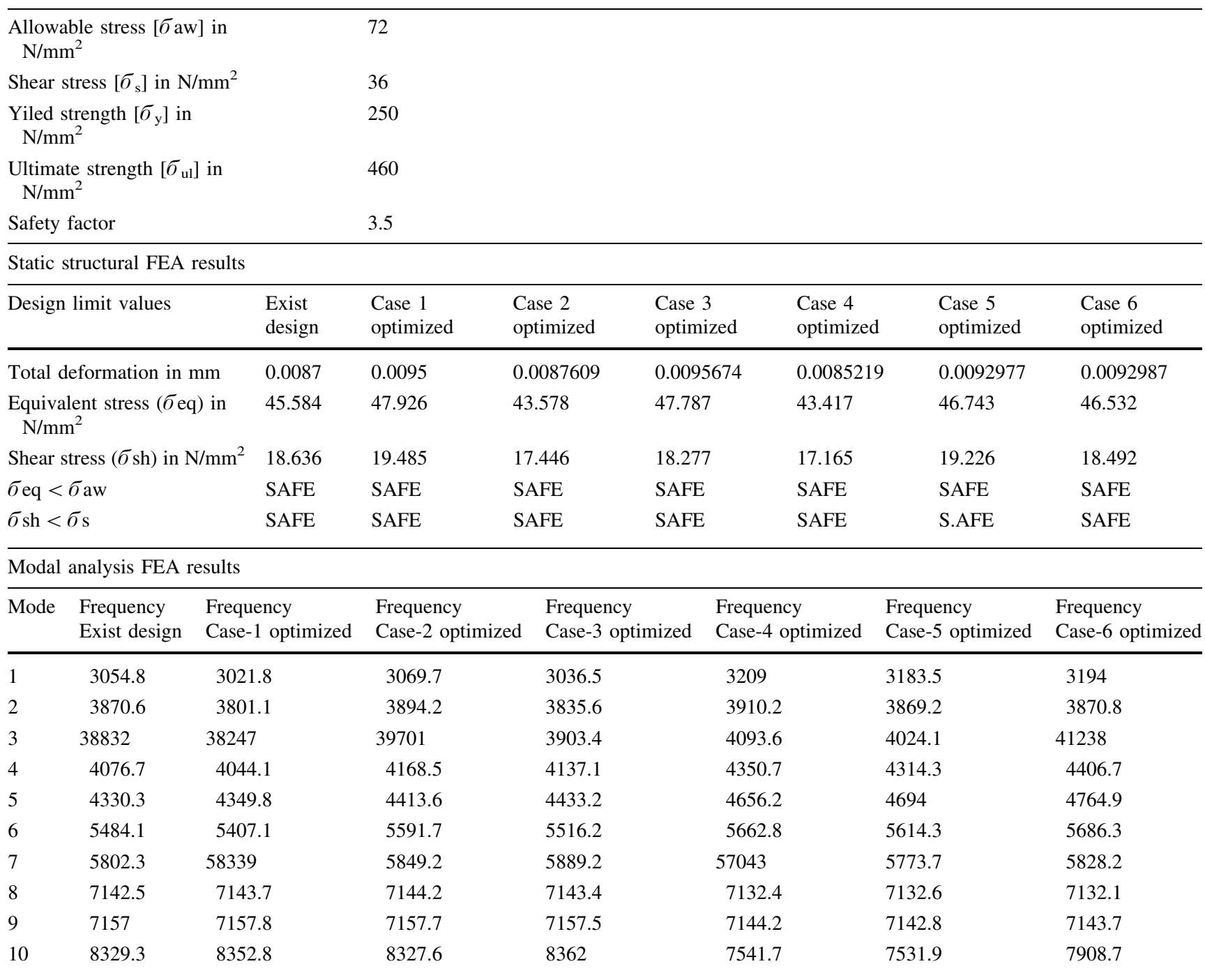

All the frequencies are measured in $\mathrm{Hz}$

deviation criteria are not satisfied. The overview of $\pm 5 \%$ frequency deviation criteria results are shown in Table 12.

\subsection{Static structural analysis results}

1. FEA results of optimized crankshaft compared with the existing design of the crankshaft showed that all the optimized cases were safe under static loading cases.

2. The FEA results showed that the maximum deformation appeared at the web edge of the counter weight and the maximum stress intensity appeared at the fillets between the crankshaft journal and crank cheek. However, the maximum intensity of stresses at the fillet region did not deviate from the design limit of the original crankshaft and theoretical values. Moreover all the optimized crankshaft cases were safe in static structural analysis, but optimized cases 1, 2 and 3 were more realistic, as these cases were safe in the dynamic loading conditions.

\subsection{Dynamic analysis results}

1. Modal analysis results of optimized cases of the crankshaft showed that maximum $\pm 10 \%$ of deviation in the natural frequency compared with the existing design of the crankshaft analytically.

2. With regard to the percentage of deviation in the frequencies of optimized crankshaft with existing design of the crankshaft, maximum $10 \%$ deviation occurred in all the optimized crankshaft designs, which is not realistic for safe design. Furthermore, cases 4, 5 and 6 are not safe according to the 5 and $10 \%$ 
Table 10 Percentage of frequency deviation with existing design

\begin{tabular}{lllllr}
\hline \% of frequency deviation with existing design & & & \\
\hline Case 1 optimized & Case 2 optimized & Case 3 optimized & Case 4 optimized & Case 5 optimized & Case 6 optimized \\
\hline 1.08 & 0.49 & 0.60 & 4.81 & 4.04 & 4.36 \\
1.80 & 0.61 & 0.90 & 1.01 & 0.04 & 0.01 \\
1.51 & 2.19 & 0.52 & 5.14 & 3.50 & 5.83 \\
0.80 & 2.20 & 1.46 & 6.30 & 5.51 & 7.75 \\
0.45 & 1.89 & 2.32 & 7.00 & 2.32 & 9.12 \\
1.40 & 1.92 & 0.58 & 3.16 & 0.49 & 3.56 \\
0.54 & 0.80 & 1.48 & 1.69 & 0.14 & 0.44 \\
0.02 & 0.02 & 0.01 & 0.14 & 0.20 & 0.15 \\
0.01 & 0.01 & 0.01 & 0.18 & 9.57 & 0.19 \\
0.28 & 0.02 & 0.39 & 9.46 & 5.05
\end{tabular}

Table 11 10\% Criteria of frequency deviation with existing design

\begin{tabular}{llllll}
\hline $10 \%$ of frequency deviation & & & & \\
\hline Case-1 optimized & Case-2 optimized & Case-3 optimized & Case-4 optimized & Case-5 optimized & Case-6 optimized \\
\hline SAFE & SAFE & SAFE & SAFE & SAFE & SAFE \\
SAFE & SAFE & SAFE & SAFE & SAFE & SAFE \\
SAFE & SAFE & SAFE & SAFE & SAFE & SAFE \\
SAFE & SAFE & SAFE & SAFE & SAFE & SAFE \\
SAFE & SAFE & SAFE & SAFE & SAFE & SAFSAFE \\
SAFE & SAFE & SAFE & SAFE & SAFE & SAFE \\
SAFE & SAFE & SAFE & SAFE & SAFE & SAFE \\
SAFE & SAFE & SAFE & SAFE & SAFE & SAFE \\
SAFE & SAFE & SAFE & SAFE & SAFE & SAFE \\
SAFE & SAFE & & & SAFE \\
\hline
\end{tabular}

Table $125 \%$ Criteria of frequency deviation with existing design

\begin{tabular}{|c|c|c|c|c|c|}
\hline \multicolumn{6}{|c|}{$5 \%$ of frequency deviation } \\
\hline Case 1 optimized & Case 2 optimized & Case 3 optimized & Case 4 optimized & Case 5 optimized & Case 6 optimized \\
\hline SAFE & SAFE & SAFE & UNSAFE & SAFE & SAFE \\
\hline SAFE & SAFE & SAFE & SAFE & SAFE & SAFE \\
\hline SAFE & SAFE & SAFE & UNSAFE & SAFE & SAFE \\
\hline SAFE & SAFE & SAFE & UNSAFE & UNSAFE & SAFE \\
\hline SAFE & SAFE & SAFE & UNSAFE & UNSAFE & SAFE \\
\hline SAFE & SAFE & SAFE & SAFE & SAFE & SAFE \\
\hline SAFE & SAFE & SAFE & SAFE & SAFE & SAFE \\
\hline SAFE & SAFE & SAFE & SAFE & SAFE & SAFE \\
\hline SAFE & SAFE & SAFE & SAFE & SAFE & SAFE \\
\hline SAFE & SAFE & SAFE & UNSAFE & UNSAFE & SAFE \\
\hline
\end{tabular}

frequency deviation with reference to the existing design of the crankshaft.

3. Modal analysis is the basic design property under dynamic conditions which helps to avoid the resonant frequency when the engine is running at maximum speed. However, dynamic results proved that the design of the crankshaft statically safe failed under dynamic condition for cases 4, 5 and 6 of the optimized crankshaft. 
4. Crankshaft frequency under different mode shapes, i.e., bending mode, torsion mode and combined mode shape, and amplitude are calculated using modal analysis-ANSYS, which showed the actual working condition deformation of the crankshaft under dynamic boundary condition.

5. Modal analysis results show that the characteristics of mode shape and its amplitude are most helpful to know the critical frequencies of the crankshaft. However, dynamic results of the crankshaft are more realistic, whereas the static results of the crankshaft shows overestimated results.

6. FEA static results showed that critical locations on the crankshaft geometry are located at the fillet region because of high stress gradient at these locations. The failure in the crankshaft may initiate at the fillet region of the crankpin and hence in future scope the fatigue phenomenon is the main mechanism of failure. It can be concluded that vibrational calculations are the most important to study the failures of the crankshaft. Hence, finite element analysis is the most effective tool to study the design and optimization of the crankshaft.

7. By studying he optimization method using geometry and shape method, the following are the weight reduction in the different optimization cases compared with the existing crankshaft.

a. Percentage of weight reduction in case 1 optimized crankshaft is $2.9 \%$

b. Percentage of weight reduction in case 2 optimized crankshaft is $0.7 \%$

c. Percentage of weight reduction in case 3 optimized crankshaft is $4.3 \%$

d. Percentage of weight reduction in case 4 optimized crankshaft is $8.5 \%$

e. Percentage of weight reduction in case 5 optimized crankshaft is $12.1 \%$

f. Percentage of weight reduction in case 6 optimized crankshaft is $13.3 \%$

\section{Future scope}

In future studies, the optimized crankshaft mode shapes and its frequencies will be validated using experimental methods. However, optimized crankshaft cases need to be verified under force vibration and fatigue failure.

Acknowledgements The author would like to thank MAN Diesel \& Turbo India Pvt Ltd. for the support extended during the dissertation curriculum.

\section{References}

1. Rao, S.S.: Mechanical vibrations. Fifth edition, Copyright 2011, Pearsom Education

2. Singh, K.: Automobile engineering vols. I and II

3. Stolarski, T., Nakasone, Y., Yoshimoto, S.: Engineering analysis with ANSYS software

4. Gokhale, N.S., Deshpande, S.S., Bedekar, S.V., Practical finite element analysis

5. Engine Crankshaft Basics (http://www.enginebasics.com/ Engine_Basics.html)

6. Balamurugan, C.M., Krishnaraj, R., Sakthivel, M., Kanthavel, K., Deepan Marudachalam M.G., Palani, R.: Computer aided modeling and optimization of crankshaft. Int. J. Sci. Eng. Res. 2(8), ISSN 2229-5518 (2011)

7. Farzin, H., Montazersadgh., Fatemi, A.: Dynamic load and stress analysis of a crankshaft. SAE International-2007-01-0258

8. Ganpule, S., Mate, S., Gokhale, U.R.: Finite element analysis approach for crankshaft optimization. Altair CAE user conference innovation through simulation, Aug 2006

9. Meng, J., Liu, Y., Liu, R.: Finite element analysis of 4-cylinder diesel crankshaft. I. J. Image, graphics and Signal Processing, Published Online Aug-2011 in MECS (http://www.mecs-press. org/) pp 22-29

10. Shah, P.D., Bhabhor, K.K.: Parametric optimization of four cylinder engine crankshaft. Int. J. Eng. Sci. Invent. 3(6):38-43 (2014)

11. Ramkumar, R., Lenin V.R., Krishnaraju, A.: Finite element analysis and optimization of crankshaft of briquette machine. Int. J. Technol. (IJEET) 21 (2015)

12. Solanki, A., Dodiya, J.: Design and stress analysis of crankshaft for single cylinder 4-stroke diesel engine. Int. J. Res. Appl. Sci. Eng. Technol. 2(V) ISSN 2321-9653. (2014)

13. Keskin, A., Aydin, K.: Crank analysis of a gasoline engine crankshaft. Gazi Univ. J. Sci. 2, ISSN 487-492 (2010)

14. Garg, R., Baghla, S.: Finite element analysis and optimization of crankshaft design. Int. J. Eng. Manag. Res. 2(6), 26-31. ISSN 2250-0758 (http://www.ijemr.net)

15. Thriveni, K., Chandraiah, J.B.: Frequency comparison and optimization of forged steel and ductile cast iron crankshafts. Int. J. Eng. Sci. Inven. 2(11), ISSN 2319-6720 (2013)

16. Thriveni, K., Chandraiah, B.J.: Modal analysis of a single cylinder 4-stroke engine crankshaft. Int. J. Sci. Res. Publ. 3(12), ISSN 2250-3153 (2013)

17. Farzin, H., Montazersadgh, Fatemi, A.: Optimization of forged steel crankshaft subjected to dynamic loading. SAE International2008-01-0432

18. Khatri, S., Kharde, D., Varpe, K.: Review on optimization of crankshaft. Int. J. Adv. Technol. Eng. Sci. 4(4), ISSN 2348-7550 (2016)

19. Pandiyan, K., Tiwari, A.: Crankshaft design methodology for diesel engines. Int. J. Innov. Res. Sci. Eng. Tech. 4(8), ISSN 2319-6710 (2015)

20. Mourelatos, Z.P.: A crank shaft system model for structural dynamic analysis of internal combustion engines

21. Kumar, K.V.S.A., Bandam, B.: Modelling and analysis of I.C engine crankshaft by using different materials and loads. Int. J. Mag. Eng. Technol. Manag. Res. 1(12), ISSN 2348-14850 (2014)

22. Desavale R.G., Patil, A.M.: Theoretical and experimental analysis of torsional and bending effect on four cylinder engine crankshafts by using finite element approach. Int. J. Eng. Res. 2(6), 379-385 ISSN 2319-6890 (2013) 
23. Gill, K.J., Roshal, P.: Durability analysis of lightweight crankshafts design using geometrically restricted finite element simulation techniques for camless engines. Int. Conf. Adv. Res. Innov. ISBN 978-93-5156-328-0 (2014)
24. Azoury, C., Kallassy, A., Combes, B., Moukarzel, I., Boudet, R.: Experimental and analytical modal analysis of a crankshaft. IOSR J. Eng. 2(4), 674-684, ISSN 2250-3021 (2012) 